Cochrane Database of Systematic Reviews

\title{
Videolaryngoscopy versus direct laryngoscopy for tracheal intubation in children (excluding neonates) (Review)
}

Abdelgadir IS, Phillips RS, Singh D, Moncreiff MP, Lumsden JL

Abdelgadir IS, Phillips RS, Singh D, Moncreiff MP, Lumsden JL.

Videolaryngoscopy versus direct laryngoscopy for tracheal intubation in children (excluding neonates).

Cochrane Database of Systematic Reviews 2017, Issue 5. Art. No.: CD011413.

DOI: 10.1002/14651858.CD011413.pub2.

www.cochranelibrary.com 
TABLE OF CONTENTS

HEADER

ABSTRACT

PLAIN LANGUAGE SUMMARY

SUMMARY OF FINDINGS

BACKGROUND

OBJECTIVES

METHODS

RESULTS

Figure 1.

Figure 2.

Figure 3.

Figure 4.

Figure 5.

Figure 6.

DISCUSSION

AUTHORS' CONCLUSIONS

ACKNOWLEDGEMENTS

REFERENCES

CHARACTERISTICS OF STUDIES

DATA AND ANALYSES

Analysis 1.1. Comparison 1 Indirect videolaryngoscope vs conventional laryngoscope for intubation of children, Outcome 1 Unsuccessful or more than 2 intubation attempts.

Analysis 1.2. Comparison 1 Indirect videolaryngoscope vs conventional laryngoscope for intubation of children, Outcome 2 Intubation time -simulated difficult airway scenario study excluded.

Analysis 1.3. Comparison 1 Indirect videolaryngoscope vs conventional laryngoscope for intubation of children, Outcome 3 Intubation time - nasal intubation study excluded.

Analysis 1.4. Comparison 1 Indirect videolaryngoscope vs conventional laryngoscope for intubation of children, Outcome 4 Successful first intubation attempts.

Analysis 1.5. Comparison 1 Indirect videolaryngoscope vs conventional laryngoscope for intubation of children, Outcome 5 Unsuccessful or more than 2 intubation attempts.

Analysis 1.6. Comparison 1 Indirect videolaryngoscope vs conventional laryngoscope for intubation of children, Outcome 6 Vocal cords score: laryngoscopic view according to the Cormack and Lehane grade (C\&L grade) - grade 1 view.

APPENDICES

CONTRIBUTIONS OF AUTHORS

DECLARATIONS OF INTEREST

SOURCES OF SUPPORT

DIFFERENCES BETWEEN PROTOCOL AND REVIEW

INDEX TERMS 
[Intervention Review]

\section{Videolaryngoscopy versus direct laryngoscopy for tracheal intubation in children (excluding neonates)}

Ibtihal S Abdelgadir ${ }^{1}$, Robert S Phillips², Davinder Singh ${ }^{3}$, Michael P Moncreiff ${ }^{4}$, Joanne L Lumsden 5

1 Paediatrics, Sidra Medical and Research Center, Doha, Qatar. ${ }^{2}$ Centre for Reviews and Dissemination, University of York, York, UK. ${ }^{3}$ Paediatric Intensive Care Unit L47, Leeds General Infirmary, Leeds, UK. ${ }^{4}$ Department of Anaesthesia, Calderdale \& Huddersfield NHS Trust, Huddersfield, UK. ${ }^{5}$ Paediatric Intensive Care Unit L47, Leeds Teaching Hospitals Trust, Leeds, UK

Contact address: Ibtihal S Abdelgadir, Paediatrics, Sidra Medical and Research Center, PO Box 26999, Doha, Qatar. ibtihalsa@hotmail.com, ibtihalsa@doctors.net.

Editorial group: Cochrane Anaesthesia Group.

Publication status and date: New, published in Issue 5, 2017.

Citation: Abdelgadir IS, Phillips RS, Singh D, Moncreiff MP, Lumsden JL. Videolaryngoscopy versus direct laryngoscopy for tracheal intubation in children (excluding neonates). Cochrane Database of Systematic Reviews 2017, Issue 5. Art. No.: CD011413. DOI: 10.1002/14651858.CD011413.pub2.

Copyright ( 2017 The Cochrane Collaboration. Published by John Wiley \& Sons, Ltd.

\section{A B S T R A C T}

\section{Background}

Direct laryngoscopy is the method currently used for tracheal intubation in children. It occasionally offers unexpectedly poor laryngeal views. Indirect laryngoscopy involves visualizing the vocal cords by means other than obtaining a direct sight, with the potential to improve outcomes. We reviewed the current available literature and performed a meta-analysis to compare direct versus indirect laryngoscopy, or videolaryngoscopy, with regards to efficacy and adverse effects.

\section{Objectives}

To assess the efficacy of indirect laryngoscopy, or videolaryngoscopy, versus direct laryngoscopy for intubation of children with regards to intubation time, number of attempts at intubation, and adverse haemodynamic responses to endotracheal intubation. We also assessed other adverse responses to intubation, such as trauma to oral, pharyngeal, and laryngeal structures, and we assessed vocal cord view scores.

\section{Search methods}

We searched the Cochrane Central Register of Controlled Trials (CENTRAL), MEDLINE, Embase, the Cumulative Index to Nursing and Allied Health Literature (CINAHL), and trial registers (www.clinicaltrials.gov and www.controlledtrials) in November 2015. We reran the search in January 2017. We added new studies of potential interest to a list of 'Studies awaiting classification' and will incorporate them into formal review findings during the review update. We performed reference checking and citation searching and contacted the authors of unpublished data to ask for more information. We applied no language restrictions.

\section{Selection criteria}

We included only randomized controlled trials. Participants were children aged 28 days to 18 years. Investigators performed intubations using any type of indirect laryngoscopes, or videolaryngoscopes, versus direct laryngoscopes.

\section{Data collection and analysis}

We used Cochrane standard methodological procedures. Two review authors independently reviewed titles, extracted data, and assessed risk of bias. 


\section{Main results}

We included 12 studies ( 803 children) in this review and meta-analysis. We identified three studies that are awaiting classification and two ongoing studies.

Trial results show that a longer intubation time was required when indirect laryngoscopy, or videolaryngoscopy, was used instead of direct laryngoscopy (12 trials; $n=798$; mean difference (MD) 5.49 seconds, $95 \%$ confidence interval $(\mathrm{Cl}) 1.37$ to $9.60 ; \mathrm{I}^{2}=90 \%$; very lowquality evidence). Researchers found no significant differences between direct and indirect laryngoscopy on assessment of success of the first attempt at intubation ( 11 trials; $n=749$; risk ratio (RR) $0.96,95 \% \mathrm{Cl} 0.91$ to $1.02 ; \mathrm{I}^{2}=67 \%$; low-quality evidence) and observed that unsuccessful intubation (five trials; $n=263$ ) was significantly increased in the indirect laryngoscopy, or videolaryngoscopy, group (RR 4.93, $95 \% \mathrm{Cl} 1.33$ to $18.31 ;\left.\right|^{2}=0 \%$; low-quality evidence). Five studies reported the effect of intubation on oxygen saturation ( $n=272 ;$ very lowquality evidence). Five children had desaturation during intubation: one from the direct laryngoscopy group and four from the indirect laryngoscopy, or videolaryngoscopy, group.

Two studies $(n=100)$ reported other haemodynamic responses to intubation (very low-quality evidence). One study reported a significant increase in heart rate five minutes after intubation in the indirect laryngoscopy group $(P=0.007)$; the other study found that the heart rate change in the direct laryngoscopy group was significantly less than the heart rate change in the indirect laryngoscopy, or videolaryngoscopy, group $(P<0.001)$. A total of five studies $(n=244$; very low-quality evidence) looked at evidence of trauma resulting from intubation. Investigators reported that only two children from the direct laryngoscopy group had trauma compared with no children in the indirect laryngoscopy, or videolaryngoscopy, group.

Use of indirect laryngoscopy, or videolaryngoscopy, improved the percentage of glottic opening (five trials; $\mathrm{n}=256$ ). Studies noted no significant difference in Cormack and Lehane score (C\&L) grade 1 (three trials; $n=190 ; \mathrm{RR} 1.06,95 \% \mathrm{Cl} 0.93$ to $1.21 ; 12=59 \%$ ).

\section{Authors' conclusions}

Evidence suggests that indirect laryngoscopy, or videolaryngoscopy, leads to prolonged intubation time with an increased rate of intubation failure when compared with direct laryngoscopy (very low-quality evidence due to imprecision, inconsistency, and study limitations). Review authors had difficulty reaching conclusions on adverse haemodynamic responses and other adverse effects of intubation, as only a few children were reported to have these outcomes. Use of indirect laryngoscopy, or videolaryngoscopy, might lead to improved vocal cord view, but marked heterogeneity between studies made it difficult for review authors to reach conclusions on this outcome.

\section{PLAIN LANGUAGE SUMMARY}

\section{Comparison of video-assisted and non-video-assisted devices for intubation of children}

\section{Background}

Children who need a general anaesthetic sometimes need a breathing tube placed in their throat, known as intubation. Intubations are also performed in emergency situations such as trauma, severe breathing difficulty, and heart dysfunction. Intubation is traditionally performed with a laryngoscope, a device that lifts the tongue to allow a direct view of the vocal cords. This is known as direct laryngoscopy. New devices have been developed that show the vocal cords through a fine video camera placed on the tip of the device; this is known as indirect laryngoscopy, or videolaryngoscopy.

Indirect laryngoscopes, or videolaryngoscopes, are thought to provide a better view of the vocal cords when compared with direct laryngoscopes, but whether this equipment allows easier placement of the breathing tube remains unclear.

\section{Study characteristics}

We reviewed the evidence on how effective indirect laryngoscopy, or videolaryngoscopy, is when compared with direct laryngoscopy for intubation in children from 28 days to 18 years old. We found 12 randomized controlled trials ( 803 children) that met our inclusion criteria. The evidence is current to November 2015. We reran the search in January 2017 and will include the three studies awaiting classification when we update the review.

\section{Key results}

For intubation, use of indirect laryngoscopy, or videolaryngoscopy, took longer and was more likely to be unsuccessful (very low-quality evidence). No significant difference was found between direct and indirect laryngoscopy when success of the first attempt at intubation was assessed (low-quality evidence). Only a few studies reported the effect of intubation on adverse haemodynamic response, including changes in oxygen saturation, heart rate, and trauma to the mouth and windpipe. Therefore, it was difficult to conclude on the overall adverse effect (very low-quality evidence). Indirect laryngoscopy might provide better views of the vocal cords.

\section{Quality of the evidence}


We found considerable variation in results from included studies in terms of assessment of intubation time, number of attempts at intubation, number of unsuccessful intubations, adverse effects, and assessments of how well the vocal cords were seen. None of the included studies was funded by a laryngoscope manufacturer, hence minimizing the risk of other bias. The quality of the studies varied, and only a few were of highest quality. For these reasons, we graded the overall quality of evidence as very low. 


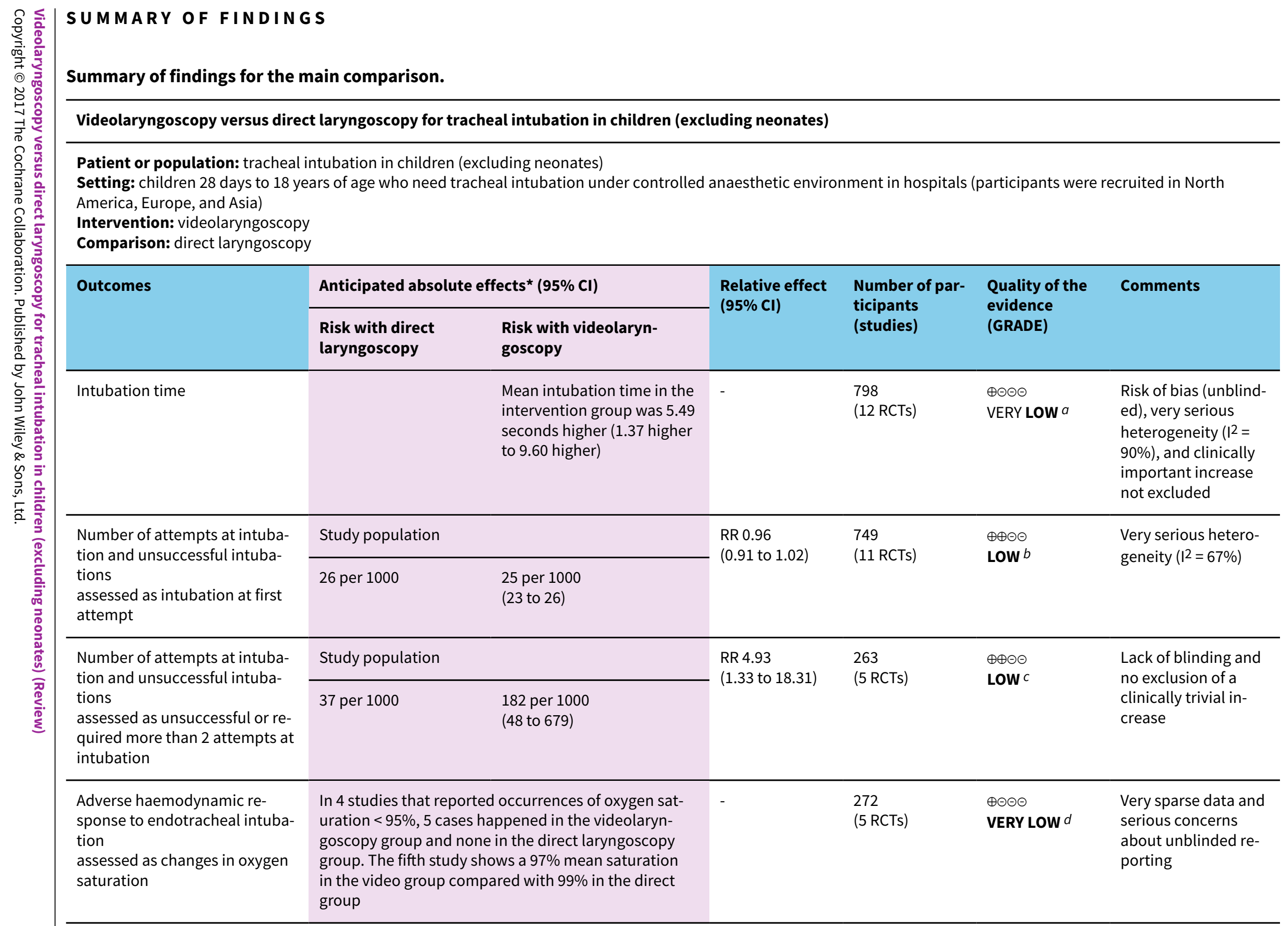

or population: tracheal intubation in children (excluding neonates)

Setting: children 28 days to 18 years of age who need tracheal intubation under controlled anaesthetic environment in hospitals (participants were recruited in North

Comparison: directlaryngoscopy 
Adverse haemodynamic response to endotracheal intubation

assessed as other adverse haemodynamic response

Other adverse effects of intubation in children, including trauma to oral, pharyngeal, and laryngeal structures, assessed by visual or laryngoscopic examination
One study reported a significant increase in heart rate after intubation with direct laryngoscopy, and the other study contradicted this and showed less of a change in heart rate in the direct group. A single study reported that systolic, diastolic, and mean arterial blood pressures were not significantly different between the 2 groups

Only 2 children from the direct laryngoscopy group were reported to have evidence of trauma as a result of the intubation process compared with no children in the indirect laryngoscopy, or videolaryngoscopy, group $\oplus \ominus \ominus \ominus$

Very sparse data and

serious concerns

about unblinded reporting

${ }^{*}$ Risk in the intervention group (and its 95\% confidence interval) is based on assumed risk in the comparison group and relative effect of the intervention (and its $95 \% \mathrm{Cl}$ )

$\mathrm{Cl}$ : confidence interval; RR: risk ratio; OR: odds ratio

\section{GRADE Working Group grades of evidence}

High quality: We are very confident that the true effect lies close to the estimate of effect

Moderate quality: We are moderately confident in the effect estimate: The true effect is likely to be close to the estimate of effect but may be substantially different Low quality: Our confidence in the effect estimate is limited: The true effect may be substantially different from the estimate of effect

Very low quality: We have very little confidence in the effect estimate: The true effect is likely to be substantially different from the estimate of effect

aDowngraded three levels owing to serious concerns about study limitation, inconsistency, and indirectness

bDowngraded two levels owing to serious inconsistency and study limitation

cDowngraded two levels owing to serious imprecision and study limitation

$d$ Downgraded three levels owing to serious imprecision and serious inconsistency and study limitation

eDowngraded three levels owing to study limitation and serious imprecision

fDowngraded three levels owing to serious imprecision, study limitation, and inconsistency 


\section{B A C K G R O U N D}

\section{Description of the condition}

Airway management with or without tracheal intubation is a lifesaving procedure and is an important step in elective anaesthesia and cardiopulmonary resuscitation. It can, however, present a challenge, especially for the less experienced and nonpaediatric anaesthetist, as the paediatric airway is substantially different from the adult airway, and obstruction leads to rapid desaturation in small infants and children (Rasmussen 2009). In the operating theatre, tracheal intubation is usually applied after induction of anaesthesia to facilitate a secure airway in patients requiring neuromuscular paralysis and positive-pressure ventilation (Zhao 2014).

A direct laryngoscope is the device most widely used to facilitate tracheal intubation (Scott 2009), but it is considered difficult to use by inexperienced personnel; it is reported that a $90 \%$ success rate requires 47 episodes of intubation practice (Mulcaster 2003). Problems with tracheal intubation were the most frequently recorded primary airway problem with difficult, delayed, and failed intubation, as were "can't intubate can't ventilate" scenarios (Woodall 2011).

Unfortunately, physical findings on examination of the airway discriminate poorly between potentially easy and difficult intubations (Shiga 2005), and direct laryngoscopy (DL) occasionally offers unexpectedly poor laryngeal views. Such difficulty, even if ultimately overcome, may result in multiple attempts at laryngoscopy and significant morbidity, such as desaturation, airway injuries, dental injuries, and cardiac arrest leading to neurological impairment. Rarely, such incidents may cause death (Cheney 1999).

\section{Description of the intervention}

Intubation was rarely performed in children before the 1940 s, by which time our understanding of childhood physiology under anaesthesia had improved, and some specialist anaesthetic equipment for children had been developed (Costarino 2005). Indirect laryngoscopy involves visualizing the person's vocal cords by a means other than obtaining a direct line of sight. Classic examples are fibreoptic and indirect laryngoscopes, or videolaryngoscopes. The curvature of the blade and the special internal arrangement of the optical components allow visualization of the glottic plane without alignment of oral, pharyngeal, and tracheal axes, which may facilitate glottic exposure (Zhao 2014). Combining the fibreoptic bronchoscope and the laryngoscope led to the development of videolaryngoscopes, which provide a videobased view of the glottic opening, with or without additional guidance of the tube towards the tracheal opening (Theiler 2013).

Many different types of indirect laryngoscopes facilitate intubation. Several manufacturers now have paediatric-specific designs, and examples of indirect laryngoscopes, or videolaryngoscopes, that are available in the full complement of paediatric sizes include the following: the Storz videolaryngoscope, GlideScope, Truview, Pentax AWS, Airtraq, and the new McGrath paediatric size 2 videolaryngoscope that was recently introduced (Fiadjoe 2014). In general, these techniques offer the advantage of avoiding the need to align the optical axis in the pharynx and mouth to visualize the entrance of the larynx (Jungbauer 2009). However, it remains unclear if this approach translates into increased success with intubation (Griesdale 2012; White 2012).

\section{How the intervention might work}

Intubation in children is increasingly performed with indirect laryngoscopes, or videolaryngoscopes, and these are now emerging as important adjuncts in airway management. A video camera at the tip of the blade can potentially provide an increased angle and a magnified view of the glottis in normal and difficult paediatric airways (Vlatten 2009). Indirect laryngoscopes, or videolaryngoscopes, use magnifying mirrors, a light source, and a guide to facilitate visualization of the vocal cords and passing of the endotracheal tube. Specific to paediatric anaesthesia, it is more difficult for the trainer and the learner to share the same view during direct laryngoscopy. The excellent view and remote screen of the indirect laryngoscope, or videolaryngoscope, may therefore be particularly useful for training in these patients (MacNair 2009).

Many early paediatric indirect laryngoscopes, or videolaryngoscopes, were simply scaled down versions of the adult design. This resulted in poor views of the airway and failed intubations for infants and neonates (Fiadjoe 2014).

In adults, both mannequin and human studies have demonstrated that indirect laryngoscopy, or videolaryngoscopy, provides superior intubating conditions and requires a shorter learning curve (Vlatten 2012). Paediatric studies suggest that indirect laryngoscopy, or videolaryngoscopy, and direct laryngoscopy are equally suitable for facilitating intubation (Fiadjoe 2012; Kim 2011; Redel 2009; Vlatten 2012), but the time needed for intubation might be prolonged with videolaryngoscopy. A study in which investigators used paramedics, medical students, respiratory therapists, and nurses in the live situation of the operating room showed that indirect laryngoscopy, or videolaryngoscopy, has higher success rates and shorter times to intubation for adults (Jungbauer 2009). Moreover, available systematic reviews of adult intubation through videolaryngoscopy have shown some improvement in intubation outcomes (De Jong 2014; Griesdale 2012; Lu 2011; Su 2011). Furthermore, Lewis and colleagues published a protocol for a Cochrane systematic review that will assess the use of videolaryngoscopy in adult surgical patients (Lewis 2014).

\section{Why it is important to do this review}

Airway management and intubation are important in both elective and emergency situations for which a secure airway is required. The current practice is to use direct laryngoscopy to facilitate intubation; however, indirect laryngoscopy, or videolaryngoscopy, has the potential to facilitate successful intubation while improving intubation outcomes. Kim and associates reported that in children, videolaryngoscopy provided a view of the larynx equal to or better than that provided by the direct laryngoscope at the expense of longer intubation times (Kim 2008). Videolaryngoscopy is easier for investigators to use and results in a lower alteration in heart rate (Maharaj 2006; Riad 2012). To date, no systematic reviews have addressed the effects of indirect laryngoscopy, or videolaryngoscopy, on only paediatric intubation outcomes. A recent meta-analysis that assessed both adults and children suggested that videolaryngoscopy is a good alternative to conventional direct laryngoscopy but included only a few paediatric studies (Su 2011). 
Sun and coworkers concluded from a recent meta-analysis including both children and neonates that videolaryngoscopies were associated with improved visualization of the glottis in children with normal airways or with potentially difficult airways, but with a significantly increased incidence of failed intubation (Sun 2014). Our review excludes neonatal intubations, as children in this age group have different airway anatomy and require different intubation techniques.

It is beyond the scope of this review to address the costeffectiveness and global health or policy-based impact of this expensive and technology-dependent intervention.

\section{OB JECTIVES}

To assess the efficacy of indirect laryngoscopy, or videolaryngoscopy, versus direct laryngoscopy for intubation of children with regards to intubation time, number of attempts at intubation, and adverse haemodynamic responses to endotracheal intubation. We also assessed other responses to intubation, such as trauma to oral, pharyngeal, and laryngeal structures, and we assessed vocal cord view scores.

\section{METHODS}

\section{Criteria for considering studies for this review}

\section{Types of studies}

We included only randomized controlled trials (RCTs) that compared intubation of children with indirect laryngoscopy, or videolaryngoscopy, versus direct laryngoscopy. We excluded mannequin-simulated studies .

\section{Types of participants}

We included studies that assessed children 28 days to 18 years of age who needed to be intubated as an elective or emergency procedure. These intubations were done in the operating theatre or in a controlled anaesthetic environment.

\section{Types of interventions}

We included in this review all available studies that assessed tracheal intubation of children using any of the different types of indirect laryngoscope, or videolaryngoscope, as an intervention, compared with the control, which used a conventional method of intubation and the direct laryngoscope.

\section{Types of outcome measures}

\section{Primary outcomes}

1. Intubation time

2. Number of attempts at intubation and number of unsuccessful intubations

3. Adverse haemodynamic responses to endotracheal intubation, including changes in oxygen saturation, mean blood pressure, heart rate, and heart rhythm

\section{Secondary outcomes}

1. Other adverse effects of intubation in children, including trauma to oral, pharyngeal, and laryngeal structures assessed by visual or laryngoscopic examination

2. Vocal cord view score

\section{Search methods for identification of studies}

\section{Electronic searches}

We searched the Cochrane Central Register of Controlled Trials (CENTRAL; 2015, Issue 11), MEDLINE (Ovid SP; 1946 to November 2015), Embase (Ovid SP; 1974 to November 2015), and the Cumulative Index to Nursing and Allied Health Literature (CINAHL) (EBSCO; 1982 to November 2015). We reran the search in January 2017 and will address any studies of interest when we update the review. (See Appendix 2 for the search strategy that we used in this review.) We adapted the search terms used in MEDLINE for the other database sources.

We applied no language restrictions and obtained English translation of relevant studies when needed.

\section{Searching other resources}

We searched for unpublished ongoing clinical trials at the following websites - www.clinicaltrials.gov and www.controlledtrials - in November 2015. We reran the search in January 2017 and will incorporate any studies of interest when we update the review. We searched relevant conference proceedings, abstracts, and internal reports, and we contacted authors of studies for unpublished data or studies. We reviewed reference lists for other possible clinical trials and personal collections of articles when needed.

\section{Data collection and analysis}

\section{Selection of studies}

We followed standard methods of the Cochrane Anaesthesia, Critical and Emergency Care Review Group. Two review authors (IA and MM or DS) independently assessed titles and abstracts and, when needed, full texts of identified studies to determine eligibility for inclusion in this review. We resolved disagreements by consulting with a third review author (JL). We constructed the PRISMA (Preferred Reporting Items for Systematic Reviews and Meta-Analyses) flow chart to record the number of papers retrieved and exclusions at each stage, along with reasons for inclusion or exclusion from the review (Moher 2009). We prepared the characteristics of included and excluded studies tables to present a summary of characteristics of relevant studies. We imposed no language restrictions

\section{Data extraction and management}

We obtained for assessment full-text versions of all studies that may be included in the review. We used the form provided by the Cochrane Anaesthesia, Critical and Emergency Care Group for data extraction, which two review authors (IA and DS) independently completed for eligible trials (Appendix 5). We compared extracted data for any differences, which we assessed through further discussion of the full texts of included studies, and we compared study data with extracted data. This resulted in resolution of all disagreements between review authors. We entered the data into Review Manager 5 (RevMan 5.3) for further processing and analysis.

\section{Assessment of risk of bias in included studies}

Two review authors (IA and DS) independently assessed the risk of bias for each study, using the criteria outlined in the Cochrane Handbook for Systematic Reviews of Interventions (Higgins 2011). 
We resolved disagreements by discussion or by consultation with a third review author (JL). We assessed risk of bias according to the following domains.

1. Random sequence generation (selection bias).

2. Allocation concealment (selection bias).

3. Blinding of participants and personnel (performance bias).

4. Blinding of outcome assessment (detection bias).

5. Incomplete outcome data (attrition bias).

6. Selective outcome reporting (reporting bias).

We graded each potential risk of bias as low, high, or unclear. We entered details of all judgements made regarding risk of bias assessment into the 'Risk of bias' tables included in the Characteristics of included studies tables.

\section{Measures of treatment effect}

We reported the risk ratio (RR) for dichotomous data and calculated the mean difference (MD) for continuous data. Some studies presented the results of continuous data as median, range or interquartile range, or both, so we calculated estimated means and standard deviations according to the method previously described by Hozo and colleagues (Hozo 2005).

\section{Unit of analysis issues}

We assessed only RCTs, using the participating child who needed intubation as the unit of analysis. We included no clusterrandomized trials or cross-over trials in this review.

\section{Dealing with missing data}

We contacted the authors of published studies for further clarification or for additional information when required. We used sensitivity analyses to explore the potential impact of missing data. We have highlighted all missing data within the Results section. We discussed in the review any drop-out of children after randomization, to address implications and effects on results if applicable.

\section{Assessment of heterogeneity}

We anticipated heterogeneity of studies owing to the nature of the interventions provided. We assessed this using $\mathrm{Chi}^{2}$ and $\mathrm{I}^{2}$ statistics (Higgins 2002). We investigated significant heterogeneity by performing subgroup analyses.

\section{Assessment of reporting biases}

We contacted trial authors to request missing outcome data, when suspected. We performed sensitivity analyses to explore the impact of including studies with missing data in the overall assessment of results (Egger 1997). We examined funnel plots when we identified 10 or more studies reporting on a particular outcome, to investigate the potential of reporting and publication bias.

\section{Data synthesis}

We performed statistical analyses according to recommendations of the Cochrane Anaesthesia, Critical and Emergency Care Group.
We used the Cochrane statistical package Review Manager 5 for data synthesis and analysis and reported all measures with $95 \%$ confidence intervals $(\mathrm{Cls})$. As we expected heterogeneity between studies, we undertook a meta-analysis with a random-effects model and explored the influence of predefined subgroups if we found sufficient data.

\section{Subgroup analysis and investigation of heterogeneity}

We planned to conduct subgroup analyses, when data were available, based on the following.

1. Degree of airway difficulty.

2. Age of the child.

3. Skill level of the operator.

4. Type of videolaryngoscopy equipment used.

5. Emergency versus elective intubation.

\section{Sensitivity analysis}

We performed sensitivity analyses to explore the potential impact of missing data and any methodological heterogeneity. We omitted from the meta-analysis studies with high risk of bias or variation in methods used one at a time to assess the effect on overall results. We assessed high risk of bias as described in the section entitled Risk of bias in included studies.

\section{Summary of findings and GRADE}

We used the principles of the GRADE system (Guyatt 2008) to assess the quality of the body of evidence associated with these specific outcomes.

1. Intubation time.

2. Number of attempts at intubation and number of unsuccessful intubations.

3. Adverse haemodynamic responses to endotracheal intubation in terms of oxygen saturation, mean blood pressure, and heart rate.

4. Other adverse effects of intubation in children, including trauma to oral, pharyngeal, and laryngeal structures, as assessed by visual or laryngoscopic examination.

We constructed Summary of findings for the main comparison using GRADE software. Through the GRADE approach, we appraised the quality of a body of evidence according to the extent to which one can be confident that an estimate of effect or association reflects the item being assessed. This technique accounted for within-study risk of bias (methodological quality), directness of the evidence, precision of effect estimates, and risk of publication bias.

\section{RESULTS}

\section{Description of studies}

\section{Results of the search}

We summarized search results in Figure 1. 
Figure 1. Study flow (PRISMA) diagram of included and excluded studies. We reran the search in January 2017. We found three studies of interest. These studies were added to a list of 'Studies awaiting classification' and will be incorporated into formal review findings during the review update.



We initially identified 1589 citations through searches of databases and specific websites. After screening by titles and abstracts, we first obtained full-paper copies of 66 citations that were potentially eligible for inclusion in the review. From those studies, we excluded 51 articles for further duplication or irrelevant article methods and/or study populations. We excluded three additional studies for including different age groups and different study methods, as described in the Characteristics of excluded studies table. We included 12 studies (803 participants) in our review (Figure 1). We reran searches in November 2015. Among 134 new citations, we found no additional studies of interest. We reran the search again in January 2017, using new search terms, to include all studies while excluding duplicates. Among 959 new citations, we obtained full-paper copies for 44 additional studies, from which we found three new studies of potential interest (243 participants). We added these three studies to a list of 'Studies awaiting classification' and will incorporate them into formal review findings during the review update. We will assess two ongoing studies when we update the review.

\section{Included studies}

We included in the review 12 eligible studies identified through the search (Ali 2013; Fiadjoe 2012; Inal 2010; Kim 2008; Kim 2011; MacNair 2009; Nileshwar 2010; Redel 2009; Riad 2012; Vlatten 2009; Vlatten 2012; White 2012). We summarized these studies in the Characteristics of included studies table. 


\section{Participants}

We included in the review a total of 803 children, 28 days to 18 years of age. Participants were children who were scheduled for elective procedures. None of the included studies assessed emergency intubations. Anaesthetists, who were experts in direct laryngoscopy but had variable expertise in indirect laryngoscopy, performed all intubations. We included Fiadjoe 2012, which studied healthy infants younger than 12 months of age with normal craniofacial anatomy, but the age group was $5.5 \pm 3.3$ (mean \pm SD) months, so the possibility that this study included infants younger than 28 days of age is very low. Inclusion of this study is unlikely to affect overall results of the review.

\section{Interventions or comparisons}

Different studies used different types of videolaryngoscopes. Four studies used the GlideScope videolaryngoscope (Fiadjoe 2012; Kim 2008; Kim 2011; Redel 2009). Four studies used the Airtraq videolaryngoscope (Ali 2013; Riad 2012; Vlatten 2012; White 2012). Inal 2010 used TruView EVO2, MacNair 2009 used Berci-Kaplan, Nileshwar 2010 used the Bullard laryngoscope, and Vlatten 2009 used the STORZ laryngoscope. Three studies included no muscle relaxant as part of their study protocol, but the implication of this for the intubation process was not clear (Redel 2009; Vlatten 2009; Vlatten 2012).

\section{Excluded studies}

We excluded three studies from this review, as study design (Tutuncu 2011) and population (Riveros 2013; Singh 2009) did not meet eligibility criteria for the intervention. We presented details in the Characteristics of excluded studies section.

\section{Ongoing studies}

We identified two ongoing studies and are awaiting dissemination of study results (Jamil 2015; Kim 2016). For further information, please see the Characteristics of ongoing studies table.

\section{Studies awaiting classification}

Three studies are awaiting classification (243 participants) (Cakirca 2016; Patil 2016; Vadi 2016). We will incorporate these studies into our formal review findings during the review update. For additional information, please see the Characteristics of studies awaiting classification table.

\section{Risk of bias in included studies}

Figure 2 and Figure 3 show risk of bias assessment across all 12 included studies. We have provided additional details in the risk of bias tables found in the Characteristics of included studies section.

\section{Figure 2. Risk of bias graph: review authors' judgements about each risk of bias item presented as percentages across all included studies.}

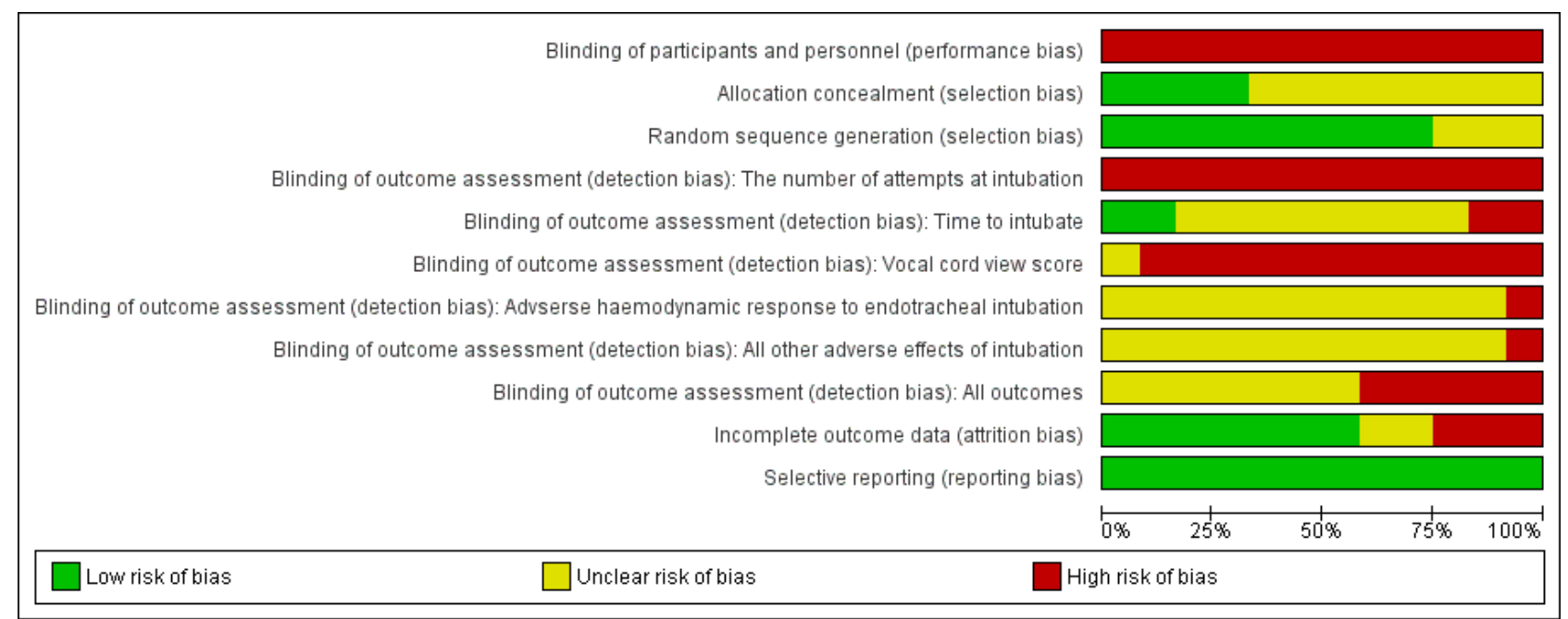


Figure 3. Risk of bias summary: review authors' judgements about each risk of bias item for each included study.

\begin{tabular}{|c|c|c|c|c|c|c|c|c|c|c|c|}
\hline & 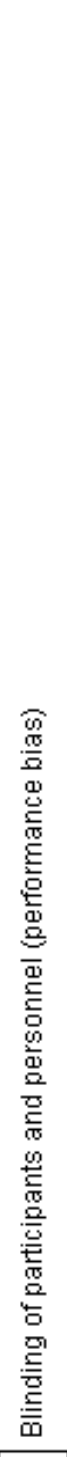 & 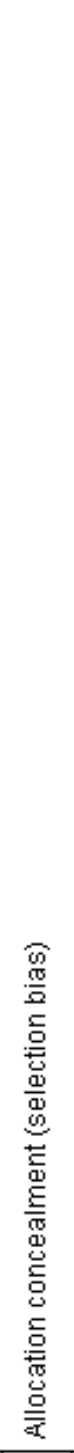 & 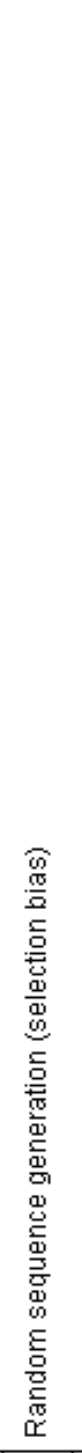 & 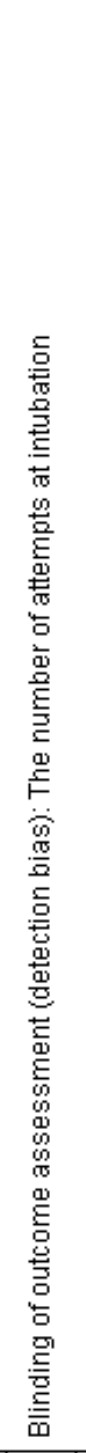 & 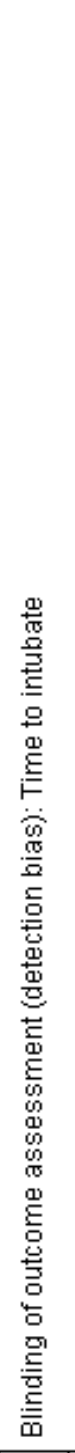 & 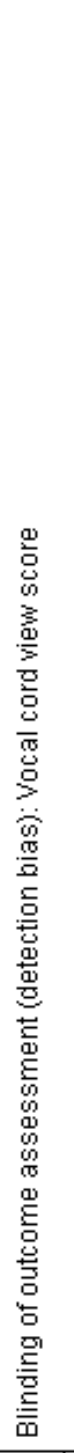 & 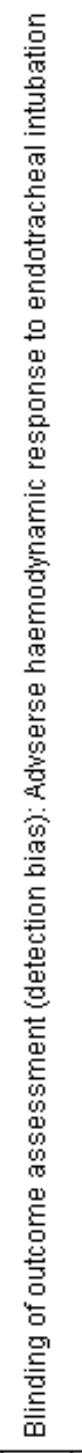 & 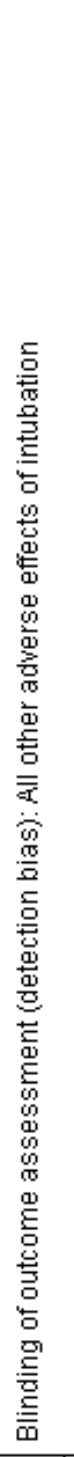 &  &  & 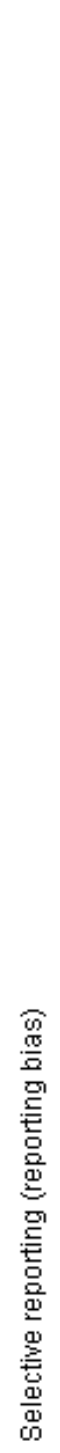 \\
\hline Ali 2013 & $\theta$ & $?$ & + & - & $?$ & $\odot$ & $?$ & $?$ & $\odot$ & $\odot$ & + \\
\hline Fiadjoe 2012 & $\Theta$ & + & + & - & O & 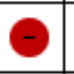 & $?$ & $?$ & O & $?$ & + \\
\hline Inal 2010 &  & + & $?$ & $\theta$ & $?$ & $\Theta$ & $?$ & $?$ & $?$ & $\odot$ & + \\
\hline Kim 2008 & 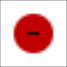 & $?$ & 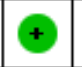 & $\theta$ & $?$ & $\Theta$ & $?$ & $?$ & - & $\odot$ & $\odot$ \\
\hline Kim 2011 & 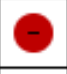 & + & + & $\odot$ & + & $\odot$ & $?$ & $?$ & $\odot$ & $\oplus$ & + \\
\hline MacNair 2009 & $\odot$ & $?$ & $?$ & $\odot$ & $?$ & $\odot$ & $?$ & $?$ & $?$ & $\odot$ & + \\
\hline Nileshwar 2010 & & $?$ & + & O & O & $\odot$ & - & - & O & - & + \\
\hline Redel 2009 & & $?$ & + & $\odot$ & $?$ & $\odot$ & $?$ & $?$ & $?$ & $\odot$ & + \\
\hline Riad 2012 & & + & $?$ & $\Theta$ & $?$ & $?$ & $?$ & $?$ & $?$ & $\odot$ & + \\
\hline Vlatten 2009 & & $?$ & $\odot$ & & $?$ & & $?$ & $?$ & $?$ & & + \\
\hline
\end{tabular}


Figure 3. (Continued)

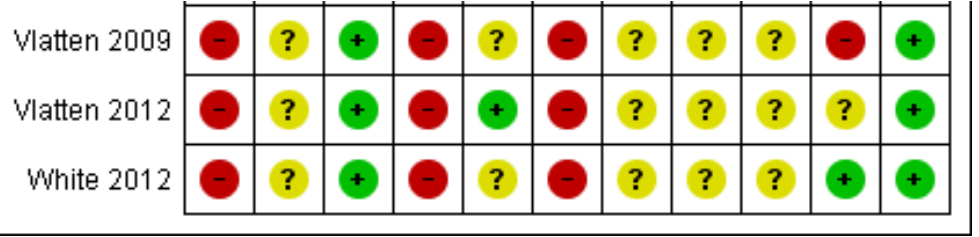

\section{Allocation}

We assessed low risk of selection bias for nine studies that provided sufficient details about randomization (Ali 2013; Fiadjoe 2012; Kim 2008; Kim 2011; Nileshwar 2010; Redel 2009; Vlatten 2009; Vlatten 2012; White 2012). We assessed low risk of allocation bias for only four studies that provided sufficient information (Inal 2010; Fiadjoe 2012; Kim 2011; Riad 2012).

\section{Blinding}

Personnel performing the intubation were not blinded to the type of device used across all 12 studies included in this review (Ali 2013; Inal 2010; Fiadjoe 2012; Kim 2008; Kim 2011; MacNair 2009; Nileshwar 2010; Redel 2009; Riad 2012; Vlatten 2009; Vlatten 2012; White 2012). Also, some outcomes were directly related to intubation, so we classified all 12 included studies as having high risk of bias. These outcomes included number of intubation attempts, vocal cord view score, and percentage of glottic opening score. Only two studies adopted good measures to reduce the risk of bias when assessing 'time to intubate' outcome measurements (Kim 2011; Vlatten 2012).

\section{Incomplete outcome data}

Seven of the included studies provided all of the results for randomized children (Ali 2013; Inal 2010; Kim 2008; Kim 2011; Redel 2009; Riad 2012; White 2012). However, five studies (Fiadjoe 2012; MacNair 2009; Nileshwar 2010; Vlatten 2009; Vlatten 2012) did not include in the analysis some of the children who had been recruited (no intention-to-treat analysis).

\section{Selective reporting}

All 12 included studies reported on all outcomes specified in the methods. Therefore, we assessed all 12 studies as having low risk of reporting bias.

\section{Other potential sources of bias}

We looked at funding by manufacturers as another source of bias; however, none of the studies reported in this review was funded by the manufacturer of an indirect laryngoscope, or videolaryngoscope.

\section{Effects of interventions}

See: Summary of findings for the main comparison

See Summary of findings for the main comparison.

\section{Comparison of indirect laryngoscopy, or videolaryngoscopy,} versus direct laryngoscopy

All 12 eligible studies reported on this comparison. They included a total of 803 children from 28 days to 18 years of age. Types of indirect laryngoscopes, or videolaryngoscopes, used included GlideScope, Airtraq, TruView EVO2, Berci-Kaplan, Bullard, and STORZ. Two studies assessed simulated difficult airway scenarios by applying manual in-line stabilization (Nileshwar 2010) or nasal intubation (Kim 2011). The remaining 10 studies evaluated orotracheal intubation in children with a presumed normal airway. Expert anaesthetists in direct laryngoscopy with variable experience in indirect laryngoscopy, or videolaryngoscopy, performed the intubations.

\section{Primary outcomes}

\section{Intubation time}

All 12 included studies reported intubation time. The pooled data synthesis included 798 children, and the definition of 'intubation time' varied between studies. Nine studies measured intubation time from introduction of the laryngoscope blade between the lips until first capnographic confirmation following intubation (Ali 2013; Fiadjoe 2012; Kim 2008; Kim 2011; MacNair 2009; Nileshwar 2010; Vlatten 2009; Vlatten 2012; White 2012).

Two studies (Inal 2010; Redel 2009) regarded intubation time as "time from the instrument entering the patient's mouth until the time it was taken out after the placement of an endotracheal tube in the trachea".

Riad 2012 reported intubation time as the period from termination of manual ventilation with a facemask to initiation of ventilation through the inserted endotracheal tube. Five studies presented results as median, range or interquartile range, or both (Fiadjoe 2012; Kim 2011; MacNair 2009; Vlatten 2009; Vlatten 2012), so we estimated mean and standard deviation according to the method described in Hozo 2005.

The pooled data synthesis and meta-analysis for this outcome showed marked heterogeneity that needed further exploration. Analysis showed that children intubated by indirect laryngoscopy, or videolaryngoscopy, needed a longer time for intubation than those intubated by direct laryngoscopy (MD 5.49 seconds, $95 \% \mathrm{Cl}$ 1.37 to $9.60 ; 1^{2}=90 \%$; very low-quality evidence; Analysis 1.1; Figure 4). 
Figure 4. Forest plot of comparison: 1 Indirect/videolaryngoscope versus conventional laryngoscope for intubation of children, outcome: 1.1 Intubation time.

\begin{tabular}{|c|c|c|c|c|c|c|c|}
\hline \multirow[b]{2}{*}{ Study or Subgroup } & \multicolumn{3}{|c|}{ Indirect laryngoscopy } & \multicolumn{3}{|c|}{ Direct laryngoscopy } & \multirow[b]{2}{*}{ Weight } \\
\hline & Mean & SD & Total & Mean & SD & Total & \\
\hline \multicolumn{8}{|c|}{ 1.1.1 Other videolaryngoscopes } \\
\hline Inal 2010 & 13.8 & 7.99 & 25 & 6.36 & 0.99 & 25 & $9.8 \%$ \\
\hline MacNair 2009 & 24.5 & 4.3 & 29 & 16.5 & 15 & 30 & $8.7 \%$ \\
\hline Nileshwar 2010 & 75.7 & 28.5 & 20 & 38.2 & 16.1 & 20 & $4.6 \%$ \\
\hline Vlatten 2009 & 28.8 & 9.8 & 27 & 22.5 & 6.5 & 26 & $9.3 \%$ \\
\hline Subtotal (95\% Cl) & & & 101 & & & 101 & $32.4 \%$ \\
\hline \multicolumn{8}{|c|}{$\begin{array}{l}\text { Heterogeneity: } \text { Tau }^{2}=31.61 ; \mathrm{Ch}^{2}=16.92, \mathrm{df}=3(\mathrm{P}=0.0007) ; \mathrm{l}^{2}=82 \% \\
\text { Test for overall effect: } Z=3.37(\mathrm{P}=0.0007)\end{array}$} \\
\hline \multicolumn{8}{|c|}{ 1.1.2 GlideScope videolaryngoscope } \\
\hline Fiadjoe 2012 & 29.9 & 11.9 & 30 & 29.6 & 14.2 & 30 & $8.2 \%$ \\
\hline Kim 2008 & 36 & 17.9 & 103 & 23.8 & 13.9 & 100 & $9.3 \%$ \\
\hline Kim 2011 & 61.8 & 3.85 & 40 & 55.4 & 5.42 & 40 & $10.2 \%$ \\
\hline Redel 2009 & 14 & 5 & 30 & 13 & 5 & 30 & $10.0 \%$ \\
\hline Subtotal $(95 \% \mathrm{Cl})$ & & & 203 & & & 200 & $37.7 \%$ \\
\hline \multicolumn{8}{|c|}{$\begin{array}{l}\text { Heterogeneity: } \text { Tau }^{2}=18.60 ; \mathrm{Ch}^{2}=23.58, \mathrm{df}=3(\mathrm{P}<0.0001) ; \mathrm{I}^{2}=87 \% \\
\text { Test for overall effect: } Z=2.15(P=0.03)\end{array}$} \\
\hline \multicolumn{8}{|c|}{ 1.1.3 Airtraq videolaryngoscope } \\
\hline Ali 2013 & 34.4 & 7.1 & 17 & 40.1 & 8.2 & 17 & $9.0 \%$ \\
\hline Riad 2012 & 22.8 & 6.2 & 25 & 51.6 & 26.7 & 25 & $6.1 \%$ \\
\hline Vlatten 2012 & 27.3 & 9 & 24 & 17 & 5 & 25 & $9.4 \%$ \\
\hline White 2012 & 47.3 & 32.6 & 30 & 26.3 & 11.5 & 30 & $5.4 \%$ \\
\hline Subtotal $(95 \% \mathrm{Cl})$ & & & 96 & & & 97 & $\mathbf{2 9 . 9} \%$ \\
\hline \multicolumn{8}{|c|}{$\begin{array}{l}\text { Heterogeneity: } \mathrm{Tau}^{2}=239.64 ; \mathrm{Chi}^{2}=64.81, \mathrm{df}=3(\mathrm{P}<0.00001) ; \mathrm{I}^{2}=95 \% \\
\text { Test for overall effect: } \mathrm{Z}=0.10(\mathrm{P}=0.92)\end{array}$} \\
\hline Total $(95 \% \mathrm{Cl})$ & & & 400 & & & 398 & $100.0 \%$ \\
\hline \multicolumn{8}{|c|}{$\begin{array}{l}\text { Heterogeneity: } \operatorname{Tau}^{2}=42.40 ; \mathrm{Chi}^{2}=114.10, \mathrm{df}=11(\mathrm{P}<0.00001) ; \mathrm{I}^{2}=90 \% \\
\text { Test for overall effect: } Z=2.61(\mathrm{P}=0.009) \\
\text { Test for subqroup differences: } \mathrm{Chi}^{2}=3.07 \mathrm{df}=2(\mathrm{P}=0.22) \mathrm{I}^{2}=34.8 \%\end{array}$} \\
\hline
\end{tabular}

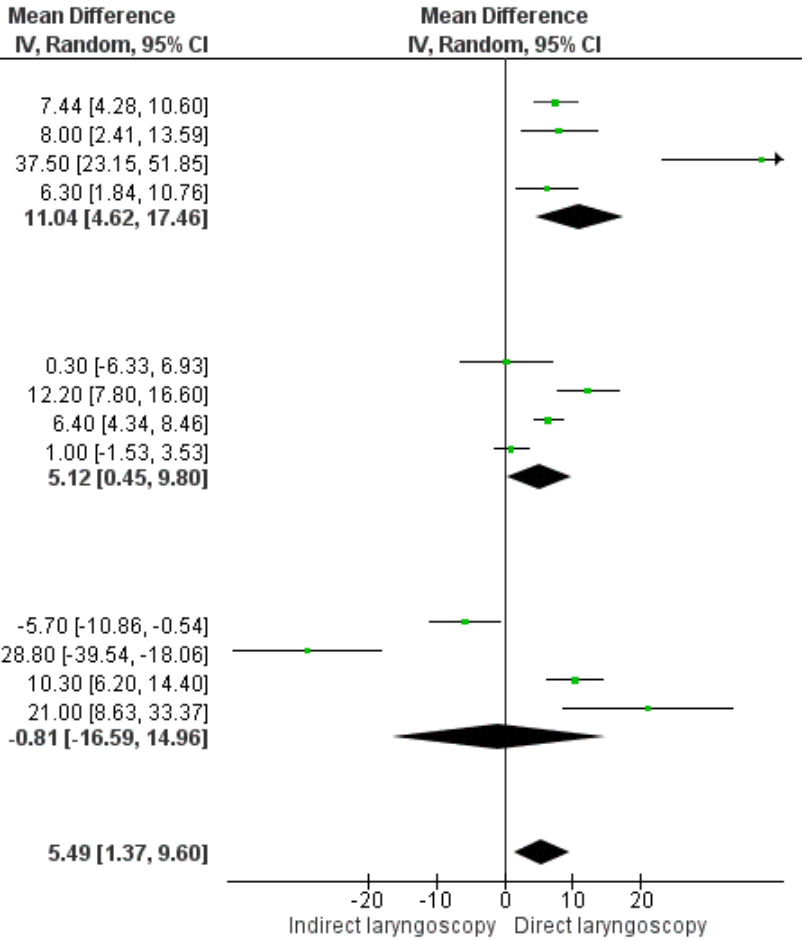

2010 from the pooled data synthesis (for high risk of bias and different methods, as recruited children had a simulated difficult airway scenario that was achieved by applying manual in-line stabilization). This resulted in no differences in overall results with regards to heterogeneity (MD 4.20 seconds, $95 \% \mathrm{Cl} 0.74$ to $7.66 ; \mathrm{I}^{2}=$ $90 \%)$. Furthermore, we omitted from the meta-analysis studies that used different definitions of intubation times and Kim 2011, which assessed nasal intubation; this revealed no differences in overall results in terms of heterogeneity (MD 5.43 seconds, 95\% Cl 1.06 to $\left.9.8 ; 1^{2}=92 \%\right)$. Sensitivity analyses did not explain the marked heterogeneity among studies, hence it is difficult for review authors to provide conclusions on overall pooled average results for this outcome.

The funnel plot showed no evidence of publication bias for this outcome (Figure 5).

\section{Sensitivity analysis}

We performed a sensitivity analysis by omitting certain studies to assess the effect on overall results. Initially, we omitted Nileshwar 
Figure 5. Funnel plot of comparison: 1 Indirect/videolaryngoscope versus conventional laryngoscope for intubation of children, outcome: 1.1 Intubation time.

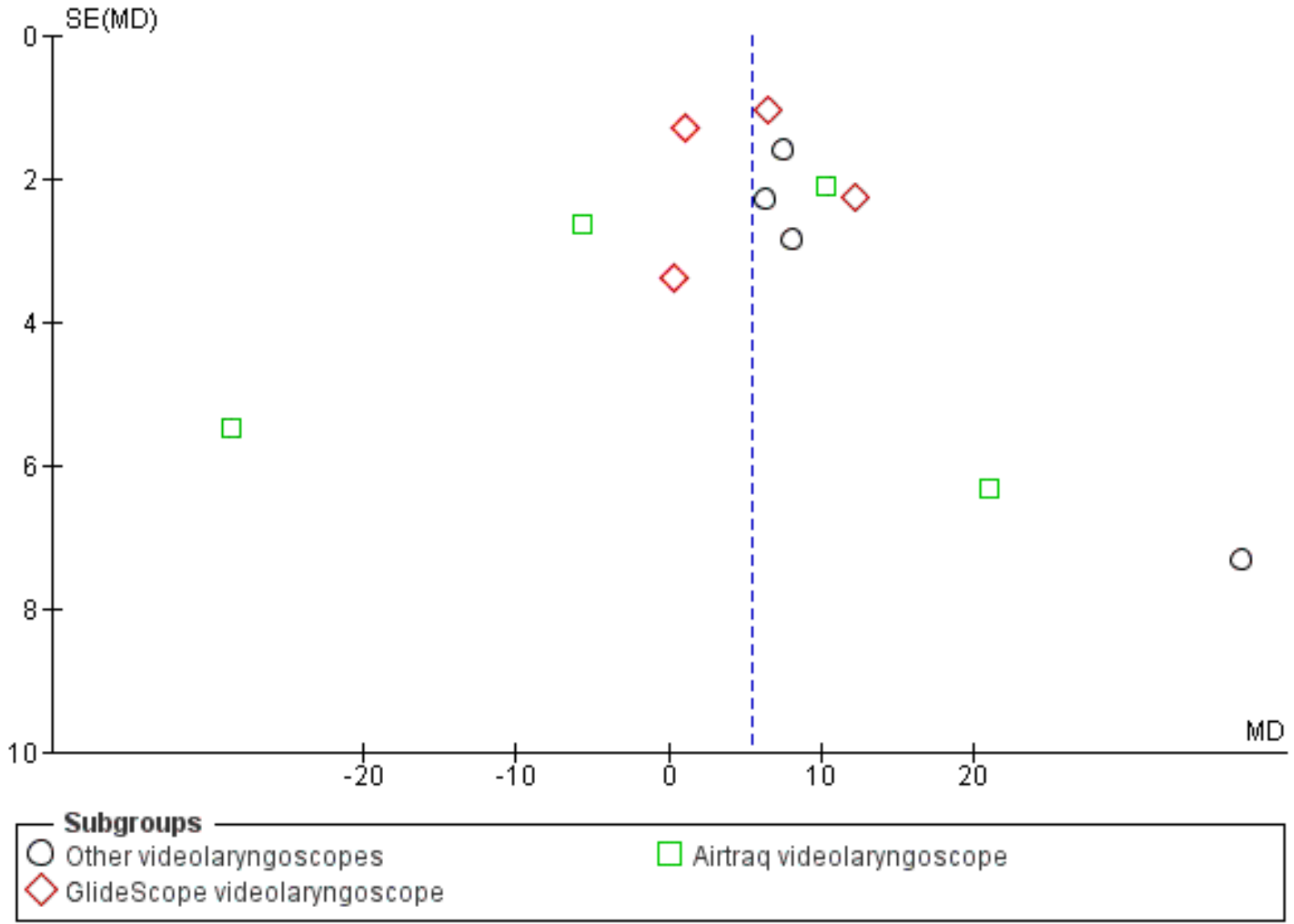

\section{Number of attempts at intubation and number of unsuccessful intubations}

Eleven studies including 749 children evaluated success on the first attempt at intubation. Investigators found no significant differences between direct and indirect laryngoscopies (RR 0.96, 95\% Cl 0.91 to $1.02 ; 1^{2}=67 \%$; low-quality evidence; Ali 2013; Inal 2010; Kim 2008; Kim 2011; Fiadjoe 2012; MacNair 2009; Nileshwar 2010; Redel 2009; Vlatten 2009; Vlatten 2012; White 2012). We have summarized these results in Analysis 1.4. It was not possible for review authors to include outcome results from Riad 2012, as the actual numbers of events were not available. Five studies that included 263 children assessed unsuccessful intubation (failure after the second attempt at intubation or oxygen desaturation or both) and found that it was significantly increased in the indirect laryngoscopy, or videolaryngoscopy, group (RR 4.93, 95\% Cl 1.33 to 18.31; $\left.\right|^{2}$ = 0\%; low-quality evidence; Ali 2013; Kim 2011; MacNair 2009; Nileshwar 2010; Vlatten 2012).

We have summarized these results in Analysis 1.5.

Funnel plot inspection for success on the first attempt at intubation shows no evidence of asymmetry (Figure 6). 
Figure 6. Funnel plot of comparison: 1 Indirect/videolaryngoscope versus conventional laryngoscope for intubation of children, outcome: 1.4 Successful first intubation attempts.

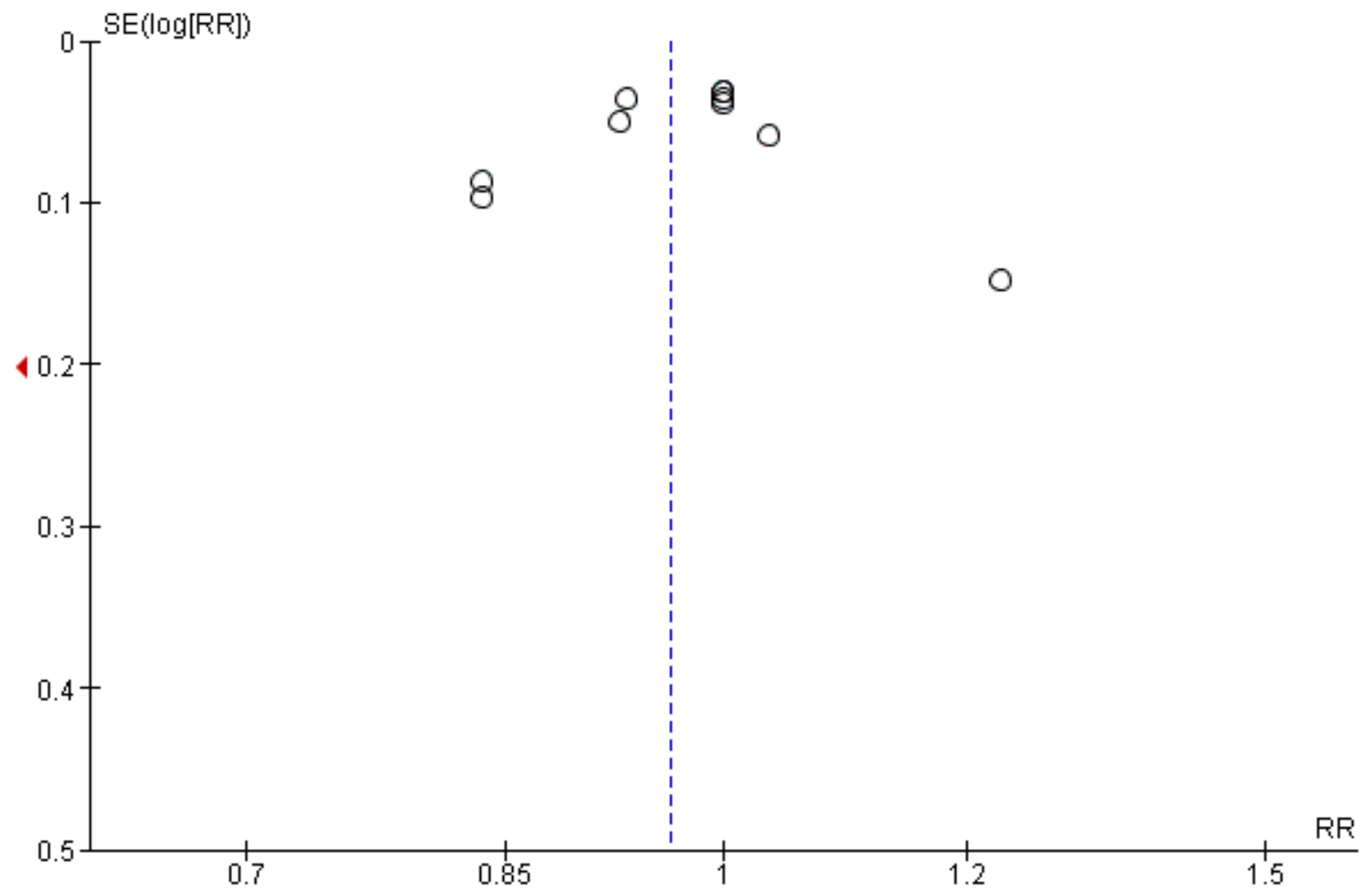

\section{Adverse haemodynamic response to endotracheal intubation}

\subsection{Effect of intubation on oxygen saturation}

Five studies including 272 children reported the effect of intubation on oxygen saturation (Inal 2010; Kim 2011; Nileshwar 2010; Vlatten 2009; Vlatten 2012; very low-quality evidence).

Inal 2010 reported lowest oxygen saturation during intubation attempts as $99.4 \% \pm 0.6 \%$ (mean \pm SD) for the direct laryngoscopy group, compared with $97.6 \% \pm 2.4 \%$ for the indirect laryngoscopy group. Investigators noted no desaturation (defined in the study as peripheral oxygen saturation < 90\%). Kim 2011 found desaturation to $<95 \%$ in one case in the indirect laryngoscopy, or videolaryngoscopy, group compared with none in the direct laryngoscopy group, and Nileshwar 2010 reported four cases in the indirect laryngoscopy, or videolaryngoscopy, group. Vlatten 2009 and Vlatten 2012 reported that oxygen saturation did not drop to below $94 \%$ during intubation in any of the children in their studies.

\subsection{Other haemodynamic responses}

Only two studies that included 100 children reported effects of intubation on other haemodynamic responses (Inal 2010; Riad 2012; very low-quality evidence).

Systolic blood pressure, diastolic blood pressure, and mean arterial pressure were not significantly different between the two groups studied by Riad 2012 ( $P=0.86,0.67$, and 0.72 , respectively), but investigators reported a significant increase in heart rate (HR) five minutes after intubation in the direct laryngoscopy group $(\mathrm{P}=$ 0.007). Inal 2010, on the other hand, showed that the HR change (difference before and after) in the direct laryngoscopy group was significantly lower than that in the indirect laryngoscopy group $(P$ $<0.001$ ) but did not provide actual data. No other studies reported these outcomes or reported heart rhythm as an outcome.

\section{Secondary outcomes}

1. Other adverse effects of intubation in children, including trauma to the airway and oral cavity

Five studies (total number of participants $=244$; very low-quality evidence) looked at evidence of trauma to the airway and oral cavity (Ali 2013; Inal 2010; Nileshwar 2010; Redel 2009; White 2012). Ali 2013 reported that only two children from the direct laryngoscopy group had evidence of trauma as a result of the intubation process compared with no children in the indirect laryngoscopy, or videolaryngoscopy, group.

\section{Vocal cord view score (percentage of glottic opening (POGO) score)}

Five of the reviewed studies, with a total of 256 children as participants, reported evaluation of the vocal cord view using a percentage score (Ali 2013; Fiadjoe 2012; Vlatten 2009; Vlatten 2012; White 2012).

We calculated estimates of means for studies for which results were presented as median, range, and/or interquartile range, as described earlier. Indirect laryngoscopy, or videolaryngoscopy, 
significantly improved the percentage of glottic opening (POGO) score in most of the studies reporting this outcome. Ali 2013 reported that the mean percentage of glottic opening was $97 \%$ in the indirect laryngoscopy group compared with $72 \%$ in the direct laryngoscopy group. The other studies yielded similar results: Fiadjoe 2012 reported a mean POGO of $90 \%$ for the indirect laryngoscopy group compared with $66.3 \%$ for the direct laryngoscopy group; and Vlatten 2009 provided a mean POGO of $95 \%$ for the indirect laryngoscopy group compared with $76.25 \%$ for the direct laryngoscopy group.

Vlatten 2012 reported a mean POGO of $97.5 \%$ of for the indirect laryngoscopy group compared with $75 \%$ for the direct laryngoscopy group, and White 2012 found no difference in POGO score reporting at $85 \%$ in both groups. We did not undertake metaanalysis owing to the very skewed nature of the data reported, which would have made any estimate of confidence intervals unlikely to be true.

\section{Vocal cord view score; laryngoscopic view according to Cormack and Lehane grade (C\&L grade)}

Six studies (including a total of 492 children as participants) evaluated vocal cord view scores according to Cormack and Lehane grade (C\&L grade) (Inal 2010; Kim 2008; Kim 2011; MacNair 2009; Nileshwar 2010; Redel 2009). However, children who were enrolled in three of the studies had been assessed by both direct and indirect laryngoscopes, hence we omitted them from the pooled data synthesis (Kim 2008; Nileshwar 2010; MacNair 2009). Studies that evaluated the C\&L view of grade 1 ( 3 trials; $n=190$ ) observed no significant differences between direct and indirect laryngoscopy, or videolaryngoscopy (RR 1.06, $95 \% \mathrm{Cl} 0.93$ to $1.21 ; 1^{2}=59 \%$; Analysis 1.6). We included only 190 children in the final data synthesis for this outcome, so results should be interpreted with caution.

\section{Subgroup analyses}

None of the included studies provided sufficient data for assessment of the following subgroups: degree of airway difficulty; age of the child; skill level of the operator; and emergency versus elective intubation.

None of the intubations were done by inexperienced staff; only experienced anaesthetists performed all intubations on children with normal airways in all included studies. This was done in a controlled anaesthetic environment, and no emergency intubations were included. Children with difficult intubations and those with high risk of anaesthesia were excluded from these studies. Data were insufficient for analysis of subgroup outcome results according to age groups.

\section{DISCUSSION}

\section{Summary of main results}

Airway complications are among the most common perioperative critical incidents in paediatric anaesthesia (Rasmussen 2009). Anaesthetists are increasingly turning to indirect laryngoscopy, or videolaryngoscopy, for both normal and difficult endotracheal intubations, mainly because videolaryngoscopy offers better views of the airway, particularly for patients who have previously undergone failed attempts at direct laryngoscopy (Fiadjoe 2014). Success with indirect laryngoscopy, or videolaryngoscopy, entails three main factors: patient factors (favourable anatomy, e.g. adequate mouth opening); provider factors (experience and skill with the device), and technical factors (e.g. optimal stylet bend angle, endotracheal tube (ETT) moulding, correct blade size selection). All of these must be optimized for smooth and successful intubation (Fiadjoe 2014).

This meta-analysis assessed the following types of paediatric indirect laryngoscopes, or videolaryngoscopes: Airtraq, Bullard, Berci-Kaplan, GlideScope, TruView, and Storz. Results of pooled data analysis show that intubation with indirect laryngoscopy, or videolaryngoscopy, was probably associated with improved visualization of the glottis, although the time to intubate was significantly prolonged when compared with direct laryngoscopy, and the quality of the evidence was very low. Of the 12 studies included in this meta-analysis, one study compared children with simulated difficult airways; this was achieved by restricting cervical spine movements (Nileshwar 2010). Moreover, the current review shows that subgroup analysis performed to assess the types of videolaryngoscopy used studied small numbers of participants or identified significant heterogeneity among studies, which indicates uncertainty about the results.

Data were insufficient to permit conclusions about the overall effects of indirect laryngoscopy, or videolaryngoscopy, with regards to adverse effects. Only two children in this review were reported to have evidence of airway/oesophageal trauma, and one study (Ali 2013) reported this. A review article reported that five children from two studies had desaturation during the intubation process (Kim 2011; Nileshwar 2010). Furthermore, only two studies reported changes in heart rate during intubation (Inal 2010; Riad 2012), and no studies reported changes in heart rhythm.

\section{Overall completeness and applicability of evidence}

We identified 12 studies that assessed more than 800 children. All studies assessed intubation times as well as visualization of the glottis. Pooled results of assessment of these two outcomes would provide a fairly good estimate of the effect. However, the trials assessed had moderate to severe heterogeneity, which indicates uncertainty regarding overall results.

\section{Quality of the evidence}

We downgraded the quality of evidence from low to very low for the main outcomes, mainly owing to inconsistency, imprecision, and/or clinical variation. These variations in study results were not explained by subgroup analysis or sensitivity analysis.

\section{Potential biases in the review process}

To our knowledge, we have identified all available studies that assessed intubation in children with indirect laryngoscopy, or videolaryngoscopy, compared with the conventional method of intubation. We searched for ongoing trials and handsearched reference lists and grey literature to reduce the risk of publication bias. We reran the search in January 2017 and found three studies of interest (with a total of 243 participants). We added these studies to a list of 'Studies awaiting classification' and will incorporate them into formal review findings during the review update. We extracted data only from full texts and included one study with a very low possibility that it included infants less than 28 days old, as the age group was reported as $5.5 \pm 3.3$ (mean \pm SD) months (Fiadjoe 2012). Inclusion of this study is unlikely to affect overall review results. Given that the $1^{2}$ statistic can be affected by 
several factors, leading to inconsistency, we believe that clinical variables within studies were the major factor that affected the overall value of the 12 statistic. In addition, imprecision as well as inconsistency between studies contributed to high value. We performed the analysis on outcomes using the high 12 statistic, but we acknowledged the low quality of evidence in Summary of findings for the main comparison.

\section{Agreements and disagreements with other studies or reviews}

A recent meta-analysis that compared the use of direct and indirect laryngoscopy in both paediatric and neonatal participants showed results similar to the findings of this review (Sun 2014). This metaanalysis revealed that although videolaryngoscopes improved glottic visualization among paediatric patients, this was achieved at the expense of prolonged intubation time and increased failures (Sun 2014). Another meta-analysis that compared direct and indirect laryngoscopy in both adults and children showed that the indirect laryngoscope, or videolaryngoscope, achieved a better view of the glottis, a similarly high rate of successful intubation, and shorter intubation time when difficulty was encountered (Su 2011). The systematic review and meta-analysis of studies that included only adult participants showed that, compared with direct laryngoscopy, Glidescope videolaryngoscopy is associated with improved glottic visualization, particularly among patients with potential or simulated difficult airways (Griesdale 2012). In a pilot study that evaluated children known to have a difficult airway, use of the GlideScope videolaryngoscope, with and without laryngeal pressure, significantly improved Cormack and Lehane grade at laryngoscopy (Karsli 2010). The recent systematic review of assessment of videolaryngoscopy among neonates identified no completed studies for inclusion in the review (Lingappan 2015). Furthermore, Lewis and colleagues published a protocol for a systematic review on assessment of use of videolaryngoscopy in adult surgical patients (Lewis 2014).

\section{AUTHORS' CONCLUSIONS}

\section{Implications for practice}

This systematic review and meta-analysis shows that assessed trials had moderate to severe heterogeneity that may have influenced overall review results. We downgraded the quality of evidence to low to very low for the main outcomes, mainly as the result of inconsistency, imprecision, and/or clinical variation. Performing indirect laryngoscopy, or videolaryngoscopy, requires skill in manipulating the endotracheal tube through a field of vision that is projected through the camera, which requires good co-ordination and possibly additional time. Currently, trainees are more often exposed to intubations performed with indirect laryngoscopy, or videolaryngoscopy, which could potentially affect overall performance and may lead to better indirect intubation outcomes. Most of the 12 included trials enrolled children with normal airways and reported that experienced staff or paediatric anaesthetists performed the intubation, so conclusions could not be drawn regarding children with difficult airways or performance of the procedure by inexperienced operators. Current evidence shows that for routine use, videolaryngoscopy might be less easier to operate than direct laryngoscopy, but it might prove beneficial in the management of difficult airways. Far more research is needed before any conclusions can be reached.

\section{Implications for research}

Additional studies are needed to evaluate the effectiveness of indirect laryngoscopy, or videolaryngoscopy, for tracheal intubation performed in settings outside the operating room and as part of difficult airway management.

\section{ACKNOWLEDGEMENTS}

We would like to thank Jane Cracknell, the Cochrane Anaesthesia, Critical and Emergency Care Group (ACE) Managing Editor, for assistance with organization of the developing review, and Karen Hovhannisyan, former Trials Search Co-ordinator, for assistance in identifying search terms for this review. We would like to thank Rodrigo Cavallazzi (Content Editor); Nathan Pace (Statistical Editor); Martin Kryspin Sørensen, Robert F Seal, Subrahmanyan Radhakrishna, and Aaron Donoghue (Peer Reviewers); and Mary Meyers (Consumer Referee) for help and editorial advice provided during preparation of this systematic review.

We would also like to thank Rodrigo Cavallazzi (Content Editor); Vibeke E Horstmann (Statistical Editor); and Subrahmanyan Radhakrishna, Aaron Donoghue, and Martin Kryspin Sørensen (Peer Reviewers) for help and editorial advice provided during preparation of the protocol (Abdelgadir 2014) for this systematic review. 


\section{RE F E R E N C E S}

\section{References to studies included in this review}

\section{Ali 2013 \{published data only\}}

Ali QE, Amir SH, Firdaus U, Siddiqui OA, Azhar AZ. A comparative study of the efficacy of Paediatric Airtraq ${ }^{\circledR}$ with conventional laryngoscope in children. Minerva Anestesiologica 2013;79(12):1366-70. [MEDLINE: 23839316]

\section{Fiadjoe 2012 \{published data only\}}

Fiadjoe JE, Gurnaney H, Dalesio N, Sussman E, Zhao H, Zhang $\mathrm{X}$, et al. A prospective randomized equivalence trial of the GlideScope Cobalt ${ }^{\circledR}$ video laryngoscope to traditional direct laryngoscopy in neonates and infants. Anesthesiology 2012;116(3):622-8. [PMID: 22270505]

\section{Inal 2010 \{published data only\}}

Inal MT, Memis D, Kargi M, Oktay Z, Sut N. Comparison of TruView EVO2 with Miller laryngoscope in paediatric patients. European Journal of Anaesthesiology 2010;27(11):950-4. [20829701]

\section{Kim 2008 \{published data only\}}

Kim JT, Na HS, Bae JY, Kim DW, Kim HS, Kim CS, et al. Glidescope video laryngoscope: a randomized clinical trial in 203 paediatric patients. British Journal of Anaesthesia 2008;101(4):531-4. [PUBMED: 18689807]

\section{Kim 2011 \{published data only\}}

Kim HJ, Kim JT, Kim HS, Kim CS, Kim SD. A comparison of Glide-Scope-video laryngoscopy and direct laryngoscopy for nasotracheal intubation in children. Paediatric Anaesthesia 2011;21(4):417-21. [PUBMED: 21244568]

\section{MacNair 2009 \{published data only\}}

Macnair D, Baraclough D, Wilson G, Bloch M, Engelhardt T. Paediatric airway management: comparing the Berci-Kaplan Video Laryngoscope with direct laryngoscopy. Paediatric Anaesthesia 2009;19(6):577-80. [PUBMED: 19645975]

\section{Nileshwar 2010 \{published data only\}}

Nileshwar A, Garg V. Comparison of Bullard laryngoscope and short-handled Macintosh laryngoscope for orotracheal intubation in pediatric patients with simulated restriction of cervical spine movements. Paediatric Anaesthesia 2010;20(12):1092-7. [PUBMED: 21199118]

\section{Redel 2009 \{published data only\}}

Redel A, Karademir F, Schlitterlau A, Frommer M, Scholtz LU, Kranke $P$, et al. Validation of the Glidescope video laryngoscope in paediatric patients. Paediatric Anaesthesia 2009;19(7):667-71. [PUBMED: 19638111]

\section{Riad 2012 \{published data only\}}

Riad W, Moussa A, Wong D. Airtraq ${ }^{\mathrm{TM}}$ versus Macintoch laryngoscope in intubation performance in the paediatric population. Saudi Journal of Anaesthesia 2012;6(4):332-5. [PUBMED: 3591549]
Vlatten 2009 \{published data only\}

Vlatten A, Aucoin S, Litz S, Macmanus B, Soder C. A comparison of the STORZ video laryngoscope and standard direct laryngoscopy for intubation in the paediatric airway - a randomized clinical trial. Paediatric Anaesthesia 2009;19(11):1102-7. [PUBMED: 19708910]

Vlatten 2012 \{published data only\}

Vlatten A, Fielding A, Bernard A, Litz S, MacManus B, Soder C, et al. Comparison of the Airtraq laryngoscope to the direct laryngoscopy in the pediatric airway. Journal of Paediatric Intensive Care 2012;2:71-6.

\section{White 2012 \{published data only\}}

White M, Marsh I, Beringer R, Nolan J, Choi A, Medlock K, et al. A randomized, controlled trial comparing the Airtraq ${ }^{\mathrm{TM}}$ optical laryngoscope with conventional laryngoscopy in infants and children. Anaesthesia 2012;67(3):226-31. [PUBMED: 22321076]

\section{References to studies excluded from this review}

Riveros 2013 \{published data only\}

Riveros R, Sung W, Sessler DI, Sanchez IP, Mendoza ML, Mascha EJ, et al. Comparison of the Truview PCD ${ }^{\mathrm{TM}}$ and the GlideScope $\left({ }^{\oplus}\right)$ video laryngoscopes with direct laryngoscopy in pediatric patients: a randomized trial. Canadian Journal of Anesthesia 2013;60(5):450. [PMID: 23435693]

Singh 2009 \{published data only\}

Singh R, Singh P, Vajifdar H. A comparison of Truview infant EVO2 laryngoscope with the Miller blade in neonates and infants. Paediatric Anaesthesia 2009;19(4):338-42.

Tutuncu 2011 \{published and unpublished data\}

Tutuncu C, Kaya G, Meyanci G, Tunali Y, Utku T, Vehid S. Comparison of Truview EVO2 and Macintosh laryngoscopes in infants. Paediatric Anaesthesia and Intensive Care 2011;28:150. [10AP2-1]

\section{References to studies awaiting assessment}

Cakirca 2016 \{published data only\}

Cakirca M, Bektas M, Demir A, Basar H, Baltaci B. A comparison of the efficacy of Macintosh laryngoscope, Truview EVO2 and McGrath videolarngoscopy in paediatric cases. Anesthesia \& Analgesia 2016;123(3S Suppl):679. [DOI: 10.1213/01.ane.0000492918.05862.ef]

\section{Patil 2016 \{published data only\}}

Patil V, Subramanya B, Kiranchand N, Bhaskar S, Dammur S. Does $\mathrm{C}-\mathrm{MAC}^{\circledR}$ video laryngoscope improve the nasotracheal intubating conditions compared to Macintosh direct laryngoscope in paediatric patients posted for tonsillectomy surgeries?. Indian Journal of Anaesthesiology 2016;60(10):732-6. [DOI: 10.4103/0019-5049.191676] 
Vadi 2016 \{published data only\}

Vadi M, Roddy K, Ghazal E, Michael Um B, Neiheisel A, Applegate R. Comparison of the GlideScope Cobalt and Storz $\mathrm{DCI}$ Video Laryngoscopes in children younger than 2 years of age during manual in-line stabilization. A randomized trainee evaluation study. Pediatric Emergency Care 2016;00(00):00. [DOI: 10.1097/PEC.0000000000000607]

\section{References to ongoing studies}

Jamil 2015 \{published data only\}

A Comparative Evaluation of Airtraq Optical Laryngoscope ${ }^{\mathrm{TM}}$ and Miller Blade in Pediatric Patients Undergoing Elective Surgery Requiring Tracheal Intubation. Ongoing study May 2013.

Kim 2016 \{published data only\}

A Comparison of McGrath MAC Videolaryngoscopy and Macintosh Laryngoscopy for Orotracheal Intubation in Children. Ongoing study July 2016.

\section{Additional references}

\section{Cheney 1999}

Domino KB, Posner KL, Caplan RA, Cheney FW. Airway injury during anaesthesia: a closed claims analysis. Anesthesiology 1999;91(6):1703-11. [PUBMED: 10598613]

\section{Costarino 2005}

Costarino T, Downes J. Paediatric anaesthesia historical perspective. Anesthesiology Clinic of North America 2005;23(4):573-95. [PUBMED: 16310652 ]

\section{De Jong 2014}

De Jong A, Molinari N, Conseil M, Coisel Y, Pouzeratte Y, Belafia F, et al. Video laryngoscopy versus direct laryngoscopy for orotracheal intubation in the intensive care unit: a systematic review and meta-analysis. Intensive Care Medicine 2014;40(5):629-39. [MEDLINE: 24556912]

\section{Egger 1997}

Egger M, Smith D, Phillips N. Meta-analysis: principles and procedures. BMJ 1997;315(7121):1533-7. [PUBMED: 9432252]

\section{Fiadjoe 2014}

Fiadjoe J, Kovatsis P. Videolaryngoscopes in pediatric anesthesia: what's new?. Minerva Anestesiologica 2014;80(1):76-82. [PUBMED: PMID: 24002465 ]

\section{Griesdale 2012}

Griesdale E, Liu D, McKinney J, Choi T. Glidescope-videolaryngoscopy versus direct laryngoscopy for endotracheal intubation: a systematic review and meta-analysis. Canadian Journal of Anaesthesia 2012;59(1):41-52. [PUBMED: 22042705]

\section{Guyatt 2008}

Guyatt H, Oxman D, Kunz R, Vist E, Falck-Ytter Y, Schünemann J, GRADE Working Group. What is "quality of evidence" and why is it important to clinicians?. BMJ 2008;336(7651):995-8.

\section{Higgins 2002}

Higgins JPT, Thompson SG, Deeks JJ, Altman DG. Measuring inconsistency in meta-analyses. BMJ 2002;327(7414):557-60.

\section{Higgins 2011}

Higgins JPT, Green S (editors). Cochrane Handbook for Systematic Reviews of Interventions Version 5.1.0 [updated March 2011]. The Cochrane Collaboration, 2011. www.cochranehandbook.org.

\section{Hozo 2005}

Hozo SP, Djulbegovic B, Hozo I. Estimating the mean and variance from the median, range, and the size of a sample. $B M C$ Medical Research Methodology 2005;20(5):13. [PUBMED: PMID: 15840177 ]

\section{Jungbauer 2009}

Jungbauer A, Schumann M, Brunkhorst V, Börgers A, Groeben $\mathrm{H}$. Expected difficult tracheal intubation: a prospective comparison of direct laryngoscopy and video laryngoscopy in 200 patients. British Journal of Anaesthesia 2009;102(4):546-50. [PUBMED: 19233881]

\section{Karsli 2010}

Karsli C, Armstrong J, John J. A comparison between the GlideScope Video Laryngoscope and direct laryngoscope in paediatric patients with difficult airways - a pilot study. Anaesthesia 2010;65:353-57. [20402873]

\section{Lewis 2014}

Lewis SR, Nicholson A, Cook TM, Smith AF. Videolaryngoscopy versus direct laryngoscopy for adult surgical patients requiring tracheal intubation for general anaesthesia. Cochrane Database of Systematic Reviews 2014, Issue 5. [DOI: 10.1002/14651858.CD011136]

\section{Lingappan 2015}

Lingappan K, Arnold J, Shaw TL, Fernandes CJ, Pammi M. Videolaryngoscopy versus direct laryngoscopy for tracheal intubation in neonates. Cochrane Database of Systematic Reviews 2015, Issue 2. [DOI: 10.1002/14651858.CD009975.pub2; MEDLINE: 25691129]

\section{Lu 2011}

Lu Y, Jiang H, Zhu YS. Airtraq laryngoscope versus conventional Macintosh laryngoscope: a systematic review and metaanalysis. Anaesthesia 2011;66(12):1160-7. [MEDLINE: 21883130]

\section{Maharaj 2006}

Maharaj CH, Costello JF, Higgins BD, Harte BH, Laffey JG. Learning and performance of tracheal intubation by novice personnel: a comparison of the Airtraq and Macintosh laryngoscope. Anaesthesia 2006;61(7):671-7. [PUBMED: 16792613]

\section{Moher 2009}

Moher D, Liberati A, Tetzlaff J, Altman DG, the PRISMA Group. Preferred reporting items for systematic reviews and metaanalyses: the PRISMA statement. BMJ 2009;339:2535. 


\section{Mulcaster 2003}

Mulcaster JT, Mills J, Hung OR, MacQuarrie K, Law JA, Pytka S, et al. Laryngoscopic intubation: learning and performance. Anesthesiology 2003;98(1):23-7. [PUBMED: 12502974 ]

\section{Rasmussen 2009}

Rasmussen L, Holm-Knudsen R. Paediatric airway management: basic aspects. Acta Anaesthesiologica Scandinavica 2009;53(1):1-9. [PUBMED: PMID: 19128325]

\section{RevMan 5.3 [Computer program]}

The Nordic Cochrane Centre, The Cochrane Collaboration. Review Manager (RevMan). Version 5.3. Copenhagen: The Nordic Cochrane Centre, The Cochrane Collaboration, 2012.

\section{Scott 2009}

Scott J, Baker PA. How did the Macintosh laryngoscope become so popular?. Paediatric Anaesthesia 2009;19 Suppl 1:24-9. [PUBMED: 19572841]

\section{Shiga 2005}

Shiga T, Wajima Z, Inoue T, Sakamoto A. Predicting difficult intubation in apparently normal patients: a meta-analysis of bedside screening test performance. Anesthesiology 2005;103(2):429-37. [PUBMED: 16052126]]

\section{Su 2011}

Su YC, Chen CC, Lee YK, Lee JY, Lin KJ. Comparison of video laryngoscopes with direct laryngoscopy for tracheal intubation: a meta-analysis of randomised trials. European Journal of Anaesthesiology 2011;28:788-95. [MEDLINE: 21897263]

\section{CHARACTERISTICS OF STUDIES}

Characteristics of included studies [ordered by study ID]

\section{Sun 2014}

Sun Y, Lu Y, Huang Y, Jiang H. Pediatric video laryngoscope versus direct laryngoscope: a meta-analysis of randomized controlled trials. Paediatric Anaesthesia 2014;24(10):1056-65. [24958249]

\section{Theiler 2013}

Theiler L, Hermann K, Schoettker P, Savoldelli G, Urwyler N, Kleine-Brueggeney M, et al. SWIVIT - Swiss video-intubation trial evaluating video-laryngoscopes in a simulated difficult airway scenario: study protocol for a multicenter prospective randomized controlled trial in Switzerland. Trials 2013;14:94. [PUBMED: 23556410]

\section{Woodall 2011}

Woodall N, Frerk C, Cook TM. Can we make airway management (even) safer? Lessons from national audit. Anaesthesia 2011;66(2):27-33. [PUBMED: 22074076]

\section{Zhao 2014}

Zhao H, Feng Y, Zhou Y. Teaching tracheal intubation: Airtraq is superior to Macintosh laryngoscope. BMC Medical Education 2014;14:144. [PUBMED: 25027257]

\section{References to other published versions of this review}

\section{Abdelgadir 2014}

Abdelgadir IS, Phillips RS, Moncreiff MP, Lumsden JL. Videolaryngoscopy versus direct laryngoscopy for tracheal intubation in children (excluding neonates). Cochrane Database of Systematic Reviews 2014, Issue 12. [DOI: 10.1002/14651858.CD011413]

Ali 2013

\begin{tabular}{ll} 
Methods & Randomized controlled trial \\
\hline Participants & $\begin{array}{l}\text { A total of } 34 \text { children } 1 \text { to } 5 \text { years of age (17 in each group) of either sex, American Society of Anesthesi- } \\
\text { ologists (ASA) I and II, requiring general anaesthesia with intubation and scheduled for elective surgery } \\
\text { were included in the study and were assigned to the Airtraq group or the conventional laryngoscope } \\
\text { group with a Macintosh blade (conventional intubation) }\end{array}$
\end{tabular}

Interventions

\begin{abstract}
Airtraq intubation vs conventional intubation). The Airtraq blade was introduced into the centre of the oral cavity and over the tongue up to the vallecula, then with a fine wrist movement from side to side or lifting the blade vertically, the glottic opening was centralized and the endotracheal tube was slid into the trachea

Routine standard monitors were applied, and anaesthesia was induced with standard technique depending on the suitability of the induction agent for corresponding age at Airtraq intubation and type of surgery. After adequate depth of anaesthesia was achieved, a neuromuscular blocking agent was administered to intubate

Excluded from the study were patients who had previous or anticipated airway problems or cardiovascular problems, were younger than 1 year of age or had any other congenital anomaly, and whose parents did not give consent for the procedure
\end{abstract}


Ali 2013 (Continued)

Outcomes

Primary outcome measure was time taken for successful oral intubation. Secondary outcome measures were number of attempts to intubate, percentage of glottic opening (POGO) score, and complications of intubation, including airway trauma as confirmed by blood staining on the tube on extubation, or blood staining on the laryngoscope after its removal from the oral cavity and oesophageal intubation

Notes

The same anaesthetist performed the procedure in both groups. The investigating anaesthetist had already attained a learning curve of intubation by Airtraq in more than 50 adult patients and in more than 10 paediatric patients including infant and neonates

Study authors certified that they had no conflicts of interest with any financial organization and declared no funding source. Study was conducted in children attending surgery at one of the hospitals in India

\section{Risk of bias}

\begin{tabular}{|c|c|c|}
\hline Bias & Authors' judgement & Support for judgement \\
\hline $\begin{array}{l}\text { Blinding of participants } \\
\text { and personnel (perfor- } \\
\text { mance bias) }\end{array}$ & High risk & Not feasible because of the nature of the intervention \\
\hline $\begin{array}{l}\text { Allocation concealment } \\
\text { (selection bias) }\end{array}$ & Unclear risk & Computer-generated random number table. No additional details \\
\hline $\begin{array}{l}\text { Random sequence genera- } \\
\text { tion (selection bias) }\end{array}$ & Low risk & Computer-generated random number table \\
\hline $\begin{array}{l}\text { Blinding of outcome as- } \\
\text { sessment (detection bias) } \\
\text { The number of attempts } \\
\text { at intubation }\end{array}$ & High risk & Not feasible to avoid because of the nature of the intervention \\
\hline $\begin{array}{l}\text { Blinding of outcome as- } \\
\text { sessment (detection bias) } \\
\text { Time to intubate }\end{array}$ & Unclear risk & No additional details \\
\hline $\begin{array}{l}\text { Blinding of outcome as- } \\
\text { sessment (detection bias) } \\
\text { Vocal cord view score }\end{array}$ & High risk & Not feasible because of the nature of the intervention \\
\hline $\begin{array}{l}\text { Blinding of outcome as- } \\
\text { sessment (detection bias) } \\
\text { Advserse haemodynamic } \\
\text { response to endotracheal } \\
\text { intubation }\end{array}$ & Unclear risk & This outcome not measured in the study \\
\hline $\begin{array}{l}\text { Blinding of outcome as- } \\
\text { sessment (detection bias) } \\
\text { All other adverse effects } \\
\text { of intubation }\end{array}$ & Unclear risk & No additional details \\
\hline $\begin{array}{l}\text { Blinding of outcome as- } \\
\text { sessment (detection bias) } \\
\text { All outcomes }\end{array}$ & High risk & Difficult because of the nature of the intervention \\
\hline $\begin{array}{l}\text { Incomplete outcome data } \\
\text { (attrition bias) }\end{array}$ & Low risk & Results from all 34 recruited participants presented \\
\hline
\end{tabular}


Ali 2013 (Continued)

All outcomes

Selective reporting (re- Low risk $\quad$ All outcomes prespecified in Methods reported
porting bias)

Fiadjoe 2012

\begin{tabular}{ll}
\hline Methods & Prospective randomized equivalence trial \\
\hline Participants & $\begin{array}{l}\text { Healthy infants (American Society of Anesthesiologists physical status I or II) with normal craniofacial } \\
\text { anatomy were recruited to obtain } 60 \text { evaluable study participants younger than } 12 \text { months of age who } \\
\text { were undergoing elective surgery requiring tracheal intubation. Participants were recruited from the } \\
\text { population of patients presenting for surgery at the tertiary care children's hospital. Infants were ex- } \\
\text { cluded from participation if they were known or suspected to be difficult to intubate, or if they required } \\
\text { a rapid sequence intubation }\end{array}$
\end{tabular}

Interventions

Following inhaled induction with sevoflurane, vecuronium $(0.1 \mathrm{mg} / \mathrm{kg})$ was administered 3 minutes before laryngoscopy with the study-assigned device. All intubations were performed with a styletted endotracheal tube. Laryngoscopy with the GlideScope was performed with the tip of the blade placed in the vallecula. Laryngoscopy with the Miller blade was performed with the blade inserted into the right labial commissure of the mouth, displacing the tongue to the left side of the mouth. The blade tip was advanced into the vallecula, and the styletted tube was passed to the right of the blade. If the view was partially obstructed by the epiglottis, the epiglottis was elevated to obtain the best possible view

Outcomes Outcomes were not subgrouped as primary and/or secondary outcomes

These outcomes were studied: time to best view (TTBV), percentage of glottic opening (POGO), endotracheal tube passage time, and intubation time. Time to best view (TTBV) was defined as the time interval between the laryngoscope passing through the teeth/gums and announcing of the best glottic exposure recorded. The laryngoscopist announced the percentage of glottic opening (POGO) score once the best glottic exposure had been obtained. Endotracheal tube passage time was defined as time to intubation minus TTBV. In the event of intubation failure, a subsequent laryngoscopy was performed and the sum of tracheal intubation times was used to determine overall intubation time

All intubations were performed by 1 of 2 attending anaesthetists, each of whom had performed more
than 50 GlideScope intubations in infants. This single-site study was done at tertiary care Children's
Hospital of Philadelphia, Pennsylvania. Support was provided solely from institutional and/or depart-
mental sources. No conflict of interest was declared

\section{Risk of bias}

\begin{tabular}{lll}
\hline Bias & Authors' judgement & Support for judgement \\
\hline $\begin{array}{l}\text { Blinding of participants } \\
\text { and personnel (perfor- } \\
\text { mance bias) }\end{array}$ & High risk & Not feasible because of the nature of the intervention \\
\hline $\begin{array}{l}\text { Allocation concealment } \\
\text { (selection bias) }\end{array}$ & Low risk & $\begin{array}{l}\text { Randomization concealed from the laryngoscopist in a sealed envelope and } \\
\text { revealed after an investigator had obtained parental consent for study partici- } \\
\text { pation }\end{array}$ \\
\hline
\end{tabular}

$\begin{array}{lll}\begin{array}{l}\text { Random sequence genera- } \\ \text { tion (selection bias) }\end{array} & \text { Low risk } & \begin{array}{l}\text { Randomization performed by a research assistant using a computer random } \\ \text { number generator to generate } 1 \text { and } 2 . \text { Number } 1 \text { assigned to GlideScope and } \\ 2 \text { to direct laryngoscopy }\end{array}\end{array}$

$\begin{aligned} & \text { Blinding of outcome as- } \\ & \text { sessment (detection bias) }\end{aligned} \quad$ High risk Not feasible because of the nature of the intervention


Fiadjoe 2012 (Continued)

The number of attempts

at intubation

\begin{tabular}{lll}
\hline $\begin{array}{l}\text { Blinding of outcome as- } \\
\text { sessment (detection bias) }\end{array}$ & High risk & $\begin{array}{l}\text { An unblinded research assistant recorded time from insertion of the random- } \\
\text { ized device past the teeth/gums until its removal after intubation as time to in- } \\
\text { Time to intubate }\end{array}$ \\
\hline
\end{tabular}

\begin{tabular}{lll}
\hline Blinding of outcome as- & High risk & Not feasible because of the nature of the intervention \\
sessment (detection bias) & &
\end{tabular}

Vocal cord view score

\begin{tabular}{|c|c|c|}
\hline $\begin{array}{l}\text { Blinding of outcome as- } \\
\text { sessment (detection bias) } \\
\text { Advserse haemodynamic } \\
\text { response to endotracheal } \\
\text { intubation }\end{array}$ & Unclear risk & This outcome not measured in the study \\
\hline $\begin{array}{l}\text { Blinding of outcome as- } \\
\text { sessment (detection bias) } \\
\text { All other adverse effects } \\
\text { of intubation }\end{array}$ & Unclear risk & $\begin{array}{l}\text { After the endotracheal tube was secured, pharynx suction was done to detect } \\
\text { the presence of pharyngeal blood. Presence of blood during suctioning record- } \\
\text { ed as none, trace, or heavy. No additional details }\end{array}$ \\
\hline
\end{tabular}

of intubation

Blinding of outcome as- $\quad$ High risk Not feasible because of the nature of the intervention
sessment (detection bias)
All outcomes

Incomplete outcome data Unclear risk

(attrition bias)

A total of 66 families consented to participate in the study. One participant

All outcomes was withdrawn before any study procedures were performed, at the discretion of the attending anaesthetist, because of laryngospasm during induction of anaesthesia. Four participants were not included because a study laryngoscopist was unavailable after consent was obtained. One additional participant was excluded because of errors in timing during intubation

Selective reporting (re- Low risk $\quad$ All outcomes prespecified in Methods section reported
porting bias)

\section{Inal 2010}

\begin{tabular}{ll}
\hline Methods & Randomized controlled trial \\
\hline Participants & $\begin{array}{l}\text { Fifty 2- to 8-year-old paediatric patients presenting for surgery requiring tracheal intubation were ran- } \\
\text { domly assigned to undergo intubation using Miller (Group M, } \mathrm{n}=25 \text { ) and TruView EVO2 laryngoscopes } \\
\text { (Group } \mathrm{T}, \mathrm{n}=25)\end{array}$ \\
& $\begin{array}{l}\text { Exclusion criteria included presence of raised intracranial pressure, high risk for pulmonary aspiration } \\
\text { such as gastric outlet obstruction, bowel stasis, hiatus hernia, coagulopathy, and presence of any dis- } \\
\text { order of the head and neck }\end{array}$ \\
\hline
\end{tabular}

Interventions

TruView EVO2 laryngoscope to be compared with intubation using a Miller laryngoscope

Anaesthesia was induced by facemask with sevoflurane and $60 \%$ nitrous oxide in oxygen. Rocuronium bromide was given at a dose of $0.8 \mathrm{mg} / \mathrm{kg}$. Anaesthesia was maintained by sevoflurane $(2.0 \%-2.5 \%)$, and fentanyl 1 to $2 \mathrm{mg} / \mathrm{kg}$. Only the oral route for intubation was chosen for all participants. Several measures were used to reduce fogging of the distal lens of the TruView EVO2, including insufflation of oxygen from the side port, warming of the blade with hot water, and use of chemical defogging agents 
Inal 2010 (Continued)

Outcomes
Primary outcome was Intubation Difficulty Scale (IDS) score. Secondary outcomes were duration of the tracheal intubation procedure, rate of successful placement of the endotracheal tube, view of the glottis at laryngoscopy according to the Cormack and Lehane grading criteria, mean arterial pressure, heart rate before and after intubation, lowest peripheral oxygen saturation during intubation attempts, and all other complications including minor lacerations and dental or other airway trauma
Two anaesthetists, each with at least 4 years of experience, performed the intubations. Each anaesthetist had performed at least 20 preliminary intubations using the TruView laryngoscope before the start of the study

Study was done at Trakya University Hospital, Edirne, Turkey. None of the review authors had any conflicts of interest, and no funding source was declared

\section{Risk of bias}

\begin{tabular}{lll}
\hline Bias & Authors' judgement & Support for judgement \\
\hline $\begin{array}{l}\text { Blinding of participants } \\
\text { and personnel (perfor- } \\
\text { mance bias) }\end{array}$ & High risk & Not feasible because of the nature of the intervention \\
\hline $\begin{array}{l}\text { Allocation concealment } \\
\text { (selection bias) }\end{array}$ & Low risk & $\begin{array}{l}\text { Randomization to intubation with TruView EVO2 or Miller laryngoscope via } \\
\text { sealed envelopes opened by the anaesthetist in the operating room }\end{array}$ \\
\hline $\begin{array}{l}\text { Random sequence genera- } \\
\text { tion (selection bias) }\end{array}$ & Unclear risk & $\begin{array}{l}\text { Randomization to intubation with TruView EVO2 or Miller laryngoscope via } \\
\text { sealed envelopes opened by the anaesthetist in the operating room; no addi- } \\
\text { tional details }\end{array}$ \\
\hline
\end{tabular}

Blinding of outcome as- High risk Not feasible because of the nature of the intervention
sessment (detection bias)

The number of attempts at intubation

\begin{tabular}{lll}
\hline $\begin{array}{l}\text { Blinding of outcome as- } \\
\text { sessment (detection bias) } \\
\text { Time to intubate }\end{array}$ & Unclear risk & No additional details \\
\hline $\begin{array}{l}\text { Blinding of outcome as- } \\
\text { sessment (detection bias) }\end{array}$ & High risk & Not feasible because of the nature of the interventio \\
Vocal cord view score & &
\end{tabular}

Blinding of outcome as- Unclear risk No additional details
sessment (detection bias) Advserse haemodynamic response to endotracheal intubation

\begin{tabular}{|c|c|c|}
\hline $\begin{array}{l}\text { Blinding of outcome as- } \\
\text { sessment (detection bias) } \\
\text { All other adverse effects } \\
\text { of intubation }\end{array}$ & Unclear risk & No additional details \\
\hline $\begin{array}{l}\text { Blinding of outcome as- } \\
\text { sessment (detection bias) } \\
\text { All outcomes }\end{array}$ & Unclear risk & No additional details \\
\hline $\begin{array}{l}\text { Incomplete outcome data } \\
\text { (attrition bias) }\end{array}$ & Low risk & Results from all randomized children presented \\
\hline
\end{tabular}


Inal 2010 (Continued)

All outcomes

Selective reporting (re- Low risk All outcomes prespecified in Methods reported
porting bias)

Kim 2008

\begin{tabular}{ll}
\hline Methods & Randomized controlled trial \\
\hline Participants & Studied 203 children 3 months to 17 years of age presenting for surgery under general anaesthesia \\
& Those with risk of pulmonary aspiration or increased intracranial pressure were excluded \\
\hline Interventions & Direct laryngoscopy group with a Macintosh blade (Group DL) or GlideScope group (Group GS) \\
$\begin{array}{l}\text { Participants were not premedicated. After administration of atropine } 0.02 \mathrm{mg} / \mathrm{kg}, \text { anaesthesia was in- } \\
\text { duced with thiopental sodium } 5 \mathrm{mg} / \mathrm{kg} \text {, and intravenous rocuronium } 0.6 \mathrm{mg} / \mathrm{kg} \text { was } \text { admistered to } \\
\text { enable tracheal intubation. The lungs were ventilated with 4-8 vol\% sevoflurane in } 100 \% \text { oxygen with a } \\
\text { facemask before laryngoscopy }\end{array}$
\end{tabular}

\section{Outcomes}

Primary outcome was laryngoscopic view according to Cormack and Lehane grade (C\&L grade). All laryngoscopic views were graded both with and without applying the BURP manoeuvre, which includes backward, upward, and right lateral displacement of the thyroid cartilage. Secondary outcomes were time taken for tracheal intubation (TTI). If more than 1 attempt was required, participant received mask ventilation between attempts. TTI included time between attempts

Notes $\begin{aligned} & \text { Intubations were performed by } 3 \text { different anaesthetists who had used the GlideScope more than } 20 \\ & \text { times and were also skilled in conventional laryngoscopy } \\ & \text { Study was conducted in children attending Seoul National University Hospital, Korea. No conflicts of } \\ & \text { interest and no funding source were declared by study authors }\end{aligned}$

\section{Risk of bias}

\begin{tabular}{lll}
\hline Bias & Authors' judgement & Support for judgement \\
\hline $\begin{array}{l}\text { Blinding of participants } \\
\text { and personnel (perfor- } \\
\text { mance bias) }\end{array}$ & High risk & Not feasible because of the nature of the intervention \\
\hline $\begin{array}{l}\text { Allocation concealment } \\
\text { (selection bias) }\end{array}$ & Unclear risk & $\begin{array}{l}\text { Participants allocated by computer-generated randomization into direct } \\
\text { laryngoscopy group or GlideScope group (Group GS). No additional details }\end{array}$ \\
\hline $\begin{array}{l}\text { Random sequence genera- } \\
\text { tion (selection bias) }\end{array}$ & Low risk & $\begin{array}{l}\text { Participants allocated by computer-generated randomization into direct } \\
\text { laryngoscopy group or GlideScope group (Group GS) }\end{array}$ \\
\hline $\begin{array}{l}\text { Blinding of outcome as- } \\
\text { sessment (detection bias) } \\
\begin{array}{l}\text { The number of attempts } \\
\text { at intubation }\end{array}\end{array}$ & High risk & Not feasible because of the nature of the intervention \\
\hline $\begin{array}{l}\text { Blinding of outcome as- } \\
\text { sessment (detection bias) } \\
\text { Time to intubate }\end{array}$ & Unclear risk & No additional details \\
\hline $\begin{array}{l}\text { Blinding of outcome as- } \\
\text { sessment (detection bias) }\end{array}$ & High risk & Not feasible because of the nature of the intervention \\
\hline
\end{tabular}


Kim 2008 (Continued)

Vocal cord view score

Blinding of outcome as- $\quad$ Unclear risk This outcome not measured in this study
sessment (detection bias)
Advserse haemodynamic
response to endotracheal
intubation

Blinding of outcome as- $\quad$ Unclear risk $\quad$ No additional details
sessment (detection bias)
All other adverse effects
of intubation

\begin{tabular}{|c|c|c|}
\hline $\begin{array}{l}\text { Blinding of outcome as- } \\
\text { sessment (detection bias) } \\
\text { All outcomes }\end{array}$ & High risk & Not feasible because of the nature of the intervention \\
\hline
\end{tabular}

\begin{tabular}{l}
\hline $\begin{array}{l}\text { Incomplete outcome data } \\
\text { (attrition bias) }\end{array}$ \\
All outcomes risk
\end{tabular}

Selective reporting (re- Low risk All outcomes prespecified in Methods reported
porting bias)

$\operatorname{Kim} 2011$

\begin{tabular}{|c|c|}
\hline Methods & Randomized controlled trial \\
\hline \multirow[t]{3}{*}{ Participants } & $\begin{array}{l}\text { Patient cohort consisted of } 80 \text { children }<10 \text { years of age with ASA physical status I or II scheduled for } \\
\text { elective dental or facial surgery requiring nasotracheal intubation }\end{array}$ \\
\hline & $\begin{array}{l}\text { Patients were randomized into direct laryngoscope }(n=40) \text { and GlideScope videolaryngoscope }(n=40) \\
\text { groups }\end{array}$ \\
\hline & $\begin{array}{l}\text { Patients at risk for aspiration and those with upper airway abnormalities and known difficult airways } \\
\text { were excluded }\end{array}$ \\
\hline Interventions & $\begin{array}{l}\text { Comparison of the effectiveness of GlideScope videolaryngoscope (GV) and direct laryngoscope (DL) } \\
\text { for nasotracheal intubation in children. In the DL group, a size } 1 \text { Miller or Macintosh blade was used } \\
\text { for infants and small children, and a size } 2 \text { Macintosh blade for older children. In the GV group, a small } \\
\text { blade was used for children weighing < } 20 \mathrm{~kg} \text { and a medium-sized blade for children weighing more } \\
\text { than } 20 \mathrm{~kg} \text {. Anaesthesia was induced using intravenous thiopental ( } 5 \mathrm{mg} / \mathrm{kg}) \text {, atropine }(0.02 \mathrm{mg} / \mathrm{kg} \text { ), } \\
\text { and rocuronium ( } 0.6 \mathrm{mg} / \mathrm{kg} \text { ). During mask ventilation with } 4-8 \text { vol\% sevoflurane in } 100 \% \text { oxygen, the } \\
\text { selected nasal cavity was packed with swabs soaked in } 0.1 \% \text { epinephrine to prevent nasal bleeding }\end{array}$ \\
\hline
\end{tabular}

Outcomes Primary outcome was time to intubation (TTI). This was measured from the time the NTT was inserted into the nares until end-tidal $\mathrm{CO}_{2}$ was detected. Secondary outcomes were number of intubation attempts, glottic view score according to Cormack and Lehane grades, and degree of difficulty in intubation

Intubations were performed by 2 experienced anaesthetists skilled in direct laryngoscopy in children.
Before starting the study, both investigators performed 10 successful nasotracheal intubations with a
GlideScope videolaryngoscope on a mannequin, followed by successful nasotracheal intubation with
GV in 10 patients
Study was conducted in Seoul, Korea. Study authors certified that they had no conflicts of interest to
declare and named no funding source


Kim 2011 (Continued)

Risk of bias

\begin{tabular}{|c|c|c|}
\hline Bias & Authors' judgement & Support for judgement \\
\hline $\begin{array}{l}\text { Blinding of participants } \\
\text { and personnel (perfor- } \\
\text { mance bias) }\end{array}$ & High risk & Not feasible because of the nature of the intervention \\
\hline $\begin{array}{l}\text { Allocation concealment } \\
\text { (selection bias) }\end{array}$ & Low risk & $\begin{array}{l}\text { Both GlideScope videolaryngoscope (GV) and direct laryngoscope (DL) pre- } \\
\text { pared in the operating room to ensure blinding of the operator until the start } \\
\text { of intubation. Randomization performed by an assistant }\end{array}$ \\
\hline $\begin{array}{l}\text { Random sequence genera- } \\
\text { tion (selection bias) }\end{array}$ & Low risk & $\begin{array}{l}\text { Participants randomized into DL }(n=40) \text { and GV }(n=40) \text { groups with comput- } \\
\text { er-generated codes }\end{array}$ \\
\hline $\begin{array}{l}\text { Blinding of outcome as- } \\
\text { sessment (detection bias) } \\
\text { The number of attempts } \\
\text { at intubation }\end{array}$ & High risk & Not feasible because of the nature of the intervention \\
\hline $\begin{array}{l}\text { Blinding of outcome as- } \\
\text { sessment (detection bias) } \\
\text { Time to intubate }\end{array}$ & Low risk & $\begin{array}{l}\text { TTI checked by another assistant, who continuously watched a monitor while } \\
\text { standing behind the participant to blind the assistant to the participant group } \\
\text { and the intubation procedure }\end{array}$ \\
\hline $\begin{array}{l}\text { Blinding of outcome as- } \\
\text { sessment (detection bias) } \\
\text { Vocal cord view score }\end{array}$ & High risk & Not feasible because of the nature of the intervention \\
\hline $\begin{array}{l}\text { Blinding of outcome as- } \\
\text { sessment (detection bias) } \\
\text { Advserse haemodynamic } \\
\text { response to endotracheal } \\
\text { intubation }\end{array}$ & Unclear risk & This outcome not measured in this study \\
\hline $\begin{array}{l}\text { Blinding of outcome as- } \\
\text { sessment (detection bias) } \\
\text { All other adverse effects } \\
\text { of intubation }\end{array}$ & Unclear risk & This outcome not measured in this study \\
\hline $\begin{array}{l}\text { Blinding of outcome as- } \\
\text { sessment (detection bias) } \\
\text { All outcomes }\end{array}$ & High risk & Not feasible because of the nature of the intervention \\
\hline $\begin{array}{l}\text { Incomplete outcome data } \\
\text { (attrition bias) } \\
\text { All outcomes }\end{array}$ & Low risk & Results from all randomized children presented \\
\hline $\begin{array}{l}\text { Selective reporting (re- } \\
\text { porting bias) }\end{array}$ & Low risk & All outcomes prespecified in Methods reported \\
\hline
\end{tabular}

MacNair 2009

\begin{tabular}{ll}
\hline Methods & Randomized controlled trial \\
\hline Participants & A total of 60 children, 2 to 16 years of age (ASA I-II) requiring tracheal intubation
\end{tabular}


MacNair 2009 (Continued)

Exclusion criteria included known or suspected difficult intubation, emergency surgery, known neck instability, and respiratory, cardiovascular, or neuromuscular disorders

Interventions
Berci-Kaplan Video Laryngoscopy (VL) compared with conventional direct laryngoscopy (DL)

Anaesthesia was induced through an inhalational or intravenous technique. Atracurium $0.5 \mathrm{mg} / \mathrm{kg}$ was administered to facilitate tracheal intubation

The head of the participant was maintained in the standard 'sniffing' position, and no external laryngeal manipulation was applied during laryngoscopy

Primary outcome measure was difference in laryngoscopy grade between DL and VL, graded according
to the Cormack-Lehane scale
Time taken to intubate (TTI) with the second laryngoscope method was recorded as a secondary out-
come

Notes Laryngoscopy was performed by 2 experienced anaesthetists, both of whom had used the VL at least 30 times previously.

Study was conducted in Aberdeen, UK. Study authors declared no funding source and no conflicts of interest

\section{Risk of bias}

\begin{tabular}{lll}
\hline Bias & Authors' judgement & Support for judgement \\
\hline $\begin{array}{l}\text { Blinding of participants } \\
\text { and personnel (perfor- } \\
\text { mance bias) }\end{array}$ & High risk & Not feasible because of the nature of the intervention \\
\hline $\begin{array}{l}\text { Allocation concealment } \\
\text { (selection bias) }\end{array}$ & Unclear risk & $\begin{array}{l}\text { Randomization carried out with sealed envelopes, with } 30 \text { participants under- } \\
\text { going VL first, and } 30 \text { undergoing DL first. No additional information }\end{array}$ \\
\hline
\end{tabular}

\begin{tabular}{lll}
\hline $\begin{array}{l}\text { Random sequence genera- } \\
\text { tion (selection bias) }\end{array}$ & Unclear risk & $\begin{array}{l}\text { Randomization carried out with sealed envelopes, with } 30 \text { participants under- } \\
\text { going VL first, and } 30 \text { undergoing DL first. No additional information }\end{array}$ \\
\hline $\begin{array}{l}\text { Blinding of outcome as- } \\
\text { sessment (detection bias) } \\
\begin{array}{l}\text { The number of attempts } \\
\text { at intubation }\end{array}\end{array}$ & High risk & Not feasible because of the nature of the intervention \\
\end{tabular}

\begin{tabular}{|c|c|c|}
\hline $\begin{array}{l}\text { Blinding of outcome as- } \\
\text { sessment (detection bias) } \\
\text { Time to intubate }\end{array}$ & Unclear risk & No additional information \\
\hline
\end{tabular}

Blinding of outcome as- $\quad$ High risk Not feasible because of the nature of the intervention
sessment (detection bias)
Vocal cord view score

\footnotetext{
Blinding of outcome assessment (detection bias) Advserse haemodynamic response to endotracheal intubation
}

This outcome not measured in this study

\begin{tabular}{ll}
\hline Blinding of outcome as- \\
sessment (detection bias)
\end{tabular}$\quad$ Unclear risk $\quad$ This outcome not measured in this study


MacNair 2009 (Continued)

All other adverse effects

of intubation

\begin{tabular}{lll}
\hline $\begin{array}{l}\text { Blinding of outcome as- } \\
\text { sessment (detection bias) } \\
\text { All outcomes }\end{array}$ & Unclear risk & No additional information \\
\hline $\begin{array}{l}\text { Incomplete outcome data } \\
\begin{array}{l}\text { (attrition bias) } \\
\text { All outcomes }\end{array}\end{array}$ & High risk & Results from all randomized children presented \\
\hline $\begin{array}{l}\text { Selective reporting (re- } \\
\text { porting bias) }\end{array}$ & Low risk & All outcomes prespecified in Methods reported \\
\hline
\end{tabular}

Nileshwar 2010

\begin{tabular}{|c|c|}
\hline Methods & Randomized controlled trial \\
\hline Participants & $\begin{array}{l}\text { A total of } 40 \text { healthy patients, between } 2 \text { and } 10 \text { years of age, undergoing elective surgery under gener- } \\
\text { al anaesthesia and requiring orotracheal intubation were recruited for this study under simulated re- } \\
\text { striction of cervical spine movements. Most patients belonged to orthopaedic surgery and general pae- } \\
\text { diatric surgery }\end{array}$ \\
\hline & $\begin{array}{l}\text { Patients requiring rapid sequence induction of anaesthesia or presenting with anticipated difficult air- } \\
\text { way such as craniofacial anomalies or any form of airway obstruction were excluded from the study }\end{array}$ \\
\hline
\end{tabular}

Participants were randomly allocated to 1 of 2 groups: Group MB (first laryngoscopy with short-han-
dled Macintosh laryngoscope followed by paediatric Bullard laryngoscope) and Group BM (first laryn-
goscopy with paediatric Bullard laryngoscope, followed by short-handled Macintosh laryngoscope)
with manual in-line stabilization. After induction of anaesthesia and checking ability to ventilate, neu-
romuscular blockade was achieved with vecuronium bromide $0.1 \mathrm{mg} / \mathrm{kg}$

Outcomes $\begin{aligned} & \text { Outcomes measured were laryngoscopy time, time to best view, best glottic view, intubation time, } \\ & \text { number of attempts at intubation, and postoperative complications including desaturation or gross } \\ & \text { haemodynamic changes }\end{aligned}$

Notes All intubations were performed by a consultant anaesthetist skilled in endotracheal intubation with the Bullard laryngoscope and difficult airway techniques

Study was conducted in India. No funding source or conflict of interest was declared by study authors

\section{Risk of bias}

\begin{tabular}{lll}
\hline Bias & Authors' judgement & Support for judgement \\
\hline $\begin{array}{l}\text { Blinding of participants } \\
\text { and personnel (perfor- } \\
\text { mance bias) }\end{array}$ & High risk & Not feasible because of the nature of the intervention \\
\hline $\begin{array}{l}\text { Allocation concealment } \\
\text { (selection bias) }\end{array}$ & Unclear risk & $\begin{array}{l}\text { Participants randomly assigned with a random number generator. No addi- } \\
\text { tional information }\end{array}$ \\
\hline $\begin{array}{l}\text { Random sequence genera- } \\
\text { tion (selection bias) }\end{array}$ & Low risk & Participants randomly assigned with a random number generator \\
\hline $\begin{array}{l}\text { Blinding of outcome as- } \\
\text { sessment (detection bias) }\end{array}$ & High risk & Blinding not performed in the study because it was practically not feasible \\
\hline
\end{tabular}


Nileshwar 2010 (Continued) The number of attempts at intubation

\begin{tabular}{|c|c|c|}
\hline $\begin{array}{l}\text { Blinding of outcome as- } \\
\text { sessment (detection bias) } \\
\text { Time to intubate }\end{array}$ & High risk & Blinding not performed in the study because it was practically not feasible \\
\hline
\end{tabular}

\begin{tabular}{lll}
\hline Blinding of outcome as- & High risk & Blinding not performed in the study because it was practically not feasible \\
sessment (detection bias) &
\end{tabular}

Vocal cord view score

Blinding of outcome as-
sessment (detection bias)
Advserse haemodynamic
response to endotracheal
intubation

\begin{tabular}{|c|c|c|}
\hline $\begin{array}{l}\text { Blinding of outcome as- } \\
\text { sessment (detection bias) } \\
\text { All other adverse effects } \\
\text { of intubation }\end{array}$ & High risk & Blinding not performed in the study because it was practically not feasible \\
\hline $\begin{array}{l}\text { Blinding of outcome as- } \\
\text { sessment (detection bias) } \\
\text { All outcomes }\end{array}$ & High risk & Blinding not performed in the study because it was practically not feasible \\
\hline $\begin{array}{l}\text { Incomplete outcome data } \\
\text { (attrition bias) } \\
\text { All outcomes }\end{array}$ & High risk & Not all recruited children analysed \\
\hline $\begin{array}{l}\text { Selective reporting (re- } \\
\text { porting bias) }\end{array}$ & Low risk & All outcomes prespecified in Methods reported \\
\hline
\end{tabular}

Redel 2009

\begin{tabular}{ll}
\hline Methods & Randomized controlled trial \\
\hline Participants & $\begin{array}{l}\text { A total of } 60 \text { patients aged } 7 \text { months to } 10 \text { years were included and were randomly assigned to the Mac- } \\
\text { intosh or the GlideScope group } \\
\text { Exclusion criteria were increased risk of regurgitation and pulmonary aspiration, expected airway ab- } \\
\text { normalities, and history of gastroesophageal reflux }\end{array}$ \\
\hline Interventions & GlideScope laryngoscopy was compared with direct laryngoscopy \\
& For anaesthesia, fentanyl ( $1.5 \mu \mathrm{mg} / \mathrm{kg})$ was administered \\
& $\begin{array}{l}\text { For hypnosis, propofol }(2 \mathrm{mg} / \mathrm{kg}), \text { plus an additional dose, if necessary, at the discretion of the investi- } \\
\text { gator, or thiopental } 2 \mathrm{mg} / \mathrm{kg}\end{array}$ \\
\hline Outcomes & $\begin{array}{l}\text { Primary outcome for this study was intubation time. Other outcomes were airway class as described by } \\
\text { Cormack and Lehane, number of intubation attempts, and traumatic complications of intubation }\end{array}$ \\
\hline Notes & $\begin{array}{l}\text { Every anaesthetist involved in this study had an experience of at least } 100 \text { paediatric Macintosh endo- } \\
\text { tracheal intubations and } 20 \text { paediatric GlideScope intubations }\end{array}$
\end{tabular}


Redel 2009 (Continued)

Study was conducted in Germany. Study authors declared no conflicts of interest and no funding source

\section{Risk of bias}

\begin{tabular}{lll}
\hline Bias & Authors' judgement & Support for judgement \\
\hline $\begin{array}{l}\text { Blinding of participants } \\
\text { and personnel (perfor- } \\
\text { mance bias) }\end{array}$ & High risk & Not feasible because of the nature of the intervention \\
\hline $\begin{array}{l}\text { Allocation concealment } \\
\text { (selection bias) }\end{array}$ & Unclear risk & $\begin{array}{l}\text { For randomization, group assignment drawn by the nurse anaesthetist from an } \\
\text { envelope filled with } 30 \text { Macintosh sheets and } 30 \text { GlideScope sheets. No addi- } \\
\text { tional information }\end{array}$ \\
\hline
\end{tabular}

\begin{tabular}{ll}
\hline $\begin{array}{l}\text { Random sequence genera- } \\
\text { tion (selection bias) }\end{array}$ & Low risk
\end{tabular}$\quad \begin{aligned} & \text { For randomization, group assignment drawn by the nurse anaesthetist from an } \\
& \text { envelope filled with } 30 \text { Macintosh sheets and } 30 \text { GlideScope sheets. }\end{aligned}$

Blinding of outcome as- High risk Not feasible because of the nature of the intervention
sessment (detection bias) The number of attempts at intubation

\begin{tabular}{|c|c|c|}
\hline $\begin{array}{l}\text { Blinding of outcome as- } \\
\text { sessment (detection bias) } \\
\text { Time to intubate }\end{array}$ & Unclear risk & No additional information \\
\hline $\begin{array}{l}\text { Blinding of outcome as- } \\
\text { sessment (detection bias) } \\
\text { Vocal cord view score }\end{array}$ & High risk & Not feasible because of the nature of the intervention \\
\hline $\begin{array}{l}\text { Blinding of outcome as- } \\
\text { sessment (detection bias) } \\
\text { Advserse haemodynamic } \\
\text { response to endotracheal } \\
\text { intubation }\end{array}$ & Unclear risk & This outcome not measured in this study \\
\hline $\begin{array}{l}\text { Blinding of outcome as- } \\
\text { sessment (detection bias) } \\
\text { All other adverse effects } \\
\text { of intubation }\end{array}$ & Unclear risk & No additional information \\
\hline $\begin{array}{l}\text { Blinding of outcome as- } \\
\text { sessment (detection bias) } \\
\text { All outcomes }\end{array}$ & Unclear risk & No additional information \\
\hline $\begin{array}{l}\text { Incomplete outcome data } \\
\text { (attrition bias) } \\
\text { All outcomes }\end{array}$ & Low risk & Results of all randomized children presented \\
\hline $\begin{array}{l}\text { Selective reporting (re- } \\
\text { porting bias) }\end{array}$ & Low risk & All outcomes prespecified in Methods reported \\
\hline
\end{tabular}

\begin{tabular}{ll}
\hline Methods $\quad$ Randomized controlled trial \\
\hline
\end{tabular}


Riad 2012 (Continued)

Participants A total of 50 healthy children 2 to 10 years of age of American Society of Anesthesiologists class I, scheduled for elective surgery under general anaesthesia requiring endotracheal intubation

Exclusion criteria were history of difficult intubation, risk of gastric aspiration, cardiovascular disease, respiratory disease, metabolic disease, and central nervous system disease

Interventions

Intubation with the Airtraq laryngoscope or the Macintosh laryngoscope

Participants premedicated with oral midazolam $0.5 \mathrm{mg} / \mathrm{kg}$ (maximum dose of $10 \mathrm{mg}$ ), 1 hour before surgery. Baseline haemodynamic data were recorded after placement of routine monitors when participant arrived in the operating room. Anaesthesia was induced with inhalational sevoflurane in oxygen-air mixture. After induction and establishment of an intravenous line, fentanyl $2 \mu \mathrm{g} / \mathrm{kg}$, glycopyrrolate $0.04 \mu \mathrm{g} / \mathrm{kg}$, and atracurium $0.5 \mathrm{mg} / \mathrm{kg}$ were administered

\begin{tabular}{ll} 
Outcomes & $\begin{array}{l}\text { Primary outcome measure was intubation time. Secondary outcomes were number of intubation at- } \\
\text { tempts, number of optimization manoeuvres required (such as repositioning of the head or the need } \\
\text { for a second assistant to aid tracheal intubation), ease of intubation, and haemodynamic variables }\end{array}$ \\
\hline Notes & Both anaesthetists in this study had 15 or more years of experience \\
& $\begin{array}{l}\text { Study authors declared no source of support and no conflicts of interest. Not clear where the study was } \\
\text { done }\end{array}$
\end{tabular}

\section{Risk of bias}

\begin{tabular}{lll}
\hline Bias & Authors' judgement & Support for judgement \\
\hline $\begin{array}{l}\text { Blinding of participants } \\
\text { and personnel (perfor- } \\
\text { mance bias) }\end{array}$ & High risk & Not feasible because of the nature of the intervention \\
\hline $\begin{array}{l}\text { Allocation concealment } \\
\text { (selection bias) }\end{array}$ & Low risk & $\begin{array}{l}\text { Sealed envelopes opened by the anaesthetist before induction used to ran- } \\
\text { domize participants to undergo intubation with the Airtraq laryngoscope (Air- } \\
\text { traq group) or the Macintosh laryngoscope (Macintosh group) }\end{array}$ \\
\hline $\begin{array}{l}\text { Random sequence genera- } \\
\text { tion (selection bias) }\end{array}$ & Unclear risk & $\begin{array}{l}\text { Sealed envelopes opened by the anaesthetist before induction used to ran- } \\
\text { domize participants to undergo intubation with the Airtraq laryngoscope (Air- } \\
\text { traq group) or the Macintosh laryngoscope (Macintosh group). No additional } \\
\text { information }\end{array}$ \\
\hline
\end{tabular}

\begin{tabular}{lll}
\hline $\begin{array}{l}\text { Blinding of outcome as- } \\
\text { sessment (detection bias) } \\
\begin{array}{l}\text { The number of attempts } \\
\text { at intubation }\end{array}\end{array}$ & High risk & Not feasible because of the nature of the intervention \\
\hline $\begin{array}{l}\text { Blinding of outcome as- } \\
\text { sessment (detection bias) }\end{array}$ & Unclear risk & $\begin{array}{l}\text { An independent research assistant recorded all data. No additional informa- } \\
\text { time to intubate }\end{array}$
\end{tabular}

\begin{tabular}{lll}
\hline $\begin{array}{l}\text { Blinding of outcome as- } \\
\text { sessment (detection bias) } \\
\text { Vocal cord view score }\end{array}$ & Unclear risk & This outcome not measured in this study \\
\hline $\begin{array}{l}\text { Blinding of outcome as- } \\
\text { sessment (detection bias) }\end{array}$ & Unclear risk & $\begin{array}{l}\text { An independent research assistant recorded all data. No additional informa- } \\
\text { tion } \\
\begin{array}{l}\text { Advserse haemodynamic } \\
\text { response to endotracheal } \\
\text { intubation }\end{array}\end{array}$ \\
\hline
\end{tabular}


Riad 2012 (Continued)
Blinding of outcome as-
Unclear risk
This outcome not measured in this study

sessment (detection bias)

All other adverse effects

of intubation

\begin{tabular}{|c|c|c|}
\hline $\begin{array}{l}\text { Blinding of outcome as- } \\
\text { sessment (detection bias) } \\
\text { All outcomes }\end{array}$ & Unclear risk & $\begin{array}{l}\text { An independent research assistant recorded all data. No additional informa- } \\
\text { tion }\end{array}$ \\
\hline
\end{tabular}

\begin{tabular}{lll}
\hline $\begin{array}{l}\text { Incomplete outcome data } \\
\text { (attrition bias) }\end{array}$ & Low risk & Results of all randomized children presented \\
All outcomes & \\
\hline $\begin{array}{l}\text { Selective reporting (re- } \\
\text { porting bias) }\end{array}$ & Low risk & All outcomes prespecified in Methods reported \\
\hline
\end{tabular}

\section{Vlatten 2009}

\begin{tabular}{ll}
\hline Methods & Randomized controlled trial \\
\hline Participants & $\begin{array}{l}\text { A total of } 56 \text { children ( } \leq 4 \text { years of age) who were scheduled to undergo elective surgical procedures re- } \\
\text { quiring oral endotracheal intubation } \\
\text { Exclusion criteria were predicted difficult bag mask ventilation or difficult intubation, determined by } \\
\text { physical examination or a previously documented difficult airway, the need for rapid sequence induc- } \\
\text { tion, emergency endotracheal intubation, haemodynamic instability, and emergency surgery }\end{array}$
\end{tabular}

Interventions

Comparison of the STORZ videolaryngoscope vs standard direct laryngoscope for intubation in the paediatric airway

Inhalational induction with sevoflurane in nitrous oxide and oxygen or intravenous induction with propofol was performed at the discretion of the attending anaesthetist. A neuromuscular relaxant was not routinely administered ( 3 in VL and 2 in $\mathrm{DL}$ ). Before laryngoscopy, the lungs were ventilated with 48 vol\% sevoflurane in $100 \%$ oxygen for 1 minute with a facemask

\begin{tabular}{ll}
\hline Outcomes & Primary outcome was time to intubation (TTI). Secondary outcomes were time to best view (TTBV), \\
view of the larynx scored by the modified Cormack-Lehane score (CL) and the percentage of glottis \\
opening seen (POGO) score. Ease of intubation for the operator was recorded after intubation on a 10- \\
cm scaled visual analogue scale (VAS), with 0 indicating hardest and 10 easiest. Success rate, need for \\
external laryngeal manipulation to improve the view, and complications associated with laryngoscopy \\
were noted as secondary outcomes
\end{tabular}

Notes Laryngoscopists were staff and resident anaesthetists experienced in standard direct laryngoscopy who had performed a minimum of 10 mannequin intubations and 3 human intubations with the Storz $\mathrm{DCl}$ video laryngoscope before participating in the study

Study was done in Halifax, Canada, and was funded by departmental resources. Study authors declared no conflicts of interest with regard to the STORZ DCI video laryngoscope

\section{Risk of bias}

\begin{tabular}{lll}
\hline Bias & Authors' judgement & Support for judgement \\
\hline $\begin{array}{l}\text { Blinding of participants } \\
\text { and personnel (perfor- } \\
\text { mance bias) }\end{array}$ & High risk & Not feasible because of the nature of the intervention
\end{tabular}


Vlatten 2009 (Continued)

\begin{tabular}{|c|c|c|}
\hline $\begin{array}{l}\text { Allocation concealment } \\
\text { (selection bias) }\end{array}$ & Unclear risk & $\begin{array}{l}\text { Randomization carried out by drawing labelled balls from a bag (chit-in-a-box } \\
\text { technique). No additional information }\end{array}$ \\
\hline
\end{tabular}

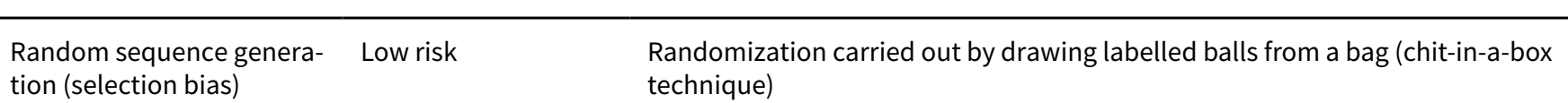

Blinding of outcome as- High risk Not feasible because of the nature of the intervention
sessment (detection bias)
The number of attempts
at intubation

\begin{tabular}{lll}
\hline $\begin{array}{l}\text { Blinding of outcome as- } \\
\text { sessment (detection bias) } \\
\text { Time to intubate }\end{array}$ & Unclear risk & Timing observed by a member of the research team with a stop watch \\
\hline $\begin{array}{l}\text { Blinding of outcome as- } \\
\text { sessment (detection bias) } \\
\text { Vocal cord view score }\end{array}$ & High risk & Not feasible because of the nature of the interventions \\
\hline
\end{tabular}

\begin{tabular}{|c|c|c|}
\hline $\begin{array}{l}\text { Blinding of outcome as- } \\
\text { sessment (detection bias) } \\
\text { Advserse haemodynamic } \\
\text { response to endotracheal } \\
\text { intubation }\end{array}$ & Unclear risk & $\begin{array}{l}\text { Timing observed by a member of the research team with a stop watch. No ad- } \\
\text { ditional information }\end{array}$ \\
\hline $\begin{array}{l}\text { Blinding of outcome as- } \\
\text { sessment (detection bias) } \\
\text { All other adverse effects } \\
\text { of intubation }\end{array}$ & Unclear risk & $\begin{array}{l}\text { Timing observed by a member of the research team with a stop watch. No ad- } \\
\text { ditional information }\end{array}$ \\
\hline
\end{tabular}

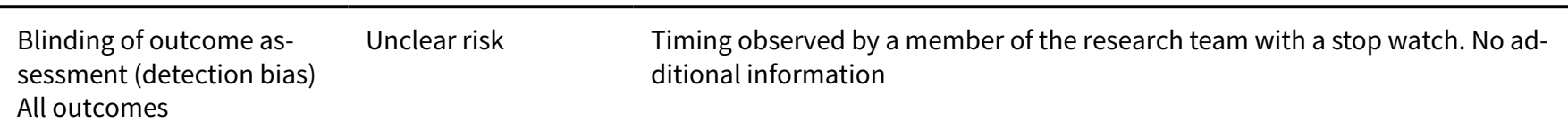

\begin{tabular}{lll}
\hline $\begin{array}{l}\text { Incomplete outcome data } \\
\text { (attrition bias) } \\
\text { All outcomes }\end{array}$ & High risk & $\begin{array}{l}\text { Three children were recruited but were not included because of a change in } \\
\text { airway management after induction. }\end{array}$ \\
\hline $\begin{array}{l}\text { Selective reporting (re- } \\
\text { porting bias) }\end{array}$ & Low risk & All outcomes prespecified in Methods reported \\
\hline
\end{tabular}

Vlatten 2012

\begin{tabular}{ll}
\hline Methods & Randomized controlled trial \\
\hline Participants & $\begin{array}{l}\text { A total of } 50 \text { children ( } \leq 5 \text { years of age) scheduled for elective surgical procedures with the requirement } \\
\text { for endotracheal intubation. Exclusion criteria were previously documented difficult airway, predicted } \\
\text { difficult bag mask ventilation, predicted difficult intubation; and need for rapid sequence induction }\end{array}$ \\
\hline Interventions & $\begin{array}{l}\text { Comparison of Airtraq optical laryngoscope vs standard laryngoscope for tracheal intubation in young } \\
\text { children with normal airway anatomy. Induction of anaesthesia was performed by inhalation of } 8 \% \\
\text { sevoflurane in } 60 \% \text { nitrous oxide and } 40 \% \text { oxygen, followed by intravenous injection of } 2 \text { mg/kg propo- } \\
\text { fol before intubation. None of the children received muscle relaxants before intubation, and all intuba- } \\
\text { tions were performed with an uncuffed tracheal tube of appropriate size for age }\end{array}$ \\
\hline
\end{tabular}


Vlatten 2012 (Continued)

Outcomes

Outcomes measured were time to intubation (TTI), time to best view (TTBV), percentage of glottis opening (POGO) score, first attempt success rate, use of external laryngeal manipulation performed by the intubator, and presence of complications associated with laryngoscopy/intubation including loss of visualization due to "fogging" or "red-out"

Each intubation in the study was performed by 1 of 5 experienced paediatric anaesthetists. Before participating in the study, each anaesthetist viewed a training video produced by the Airtraq manufacturer and performed 3 intubations on a paediatric mannequin and 5 intubations on anaesthetized children 5 years of age or younger using the Airtraq

Study was done in Halifax, Canada. Study authors declared no funding source and no conflicts of interest

\section{Risk of bias}

\begin{tabular}{lll}
\hline Bias & Authors' judgement & Support for judgement \\
\hline $\begin{array}{l}\text { Blinding of participants } \\
\begin{array}{l}\text { and personnel (perfor- } \\
\text { mance bias) }\end{array}\end{array}$ & High risk & Not feasible because of the nature of the intervention \\
\hline
\end{tabular}

\begin{tabular}{lll}
\hline $\begin{array}{l}\text { Allocation concealment } \\
\text { (selection bias) }\end{array}$ & Unclear risk & Computer-generated random number table. No additional information \\
\hline $\begin{array}{l}\text { Random sequence genera- } \\
\text { tion (selection bias) }\end{array}$ & Low risk & Computer-generated random number table \\
\hline $\begin{array}{l}\text { Blinding of outcome as- } \\
\text { sessment (detection bias) } \\
\begin{array}{l}\text { The number of attempts } \\
\text { at intubation }\end{array}\end{array}$ & High risk & \\
\hline
\end{tabular}

\begin{tabular}{|c|c|c|}
\hline $\begin{array}{l}\text { Blinding of outcome as- } \\
\text { sessment (detection bias) }\end{array}$ & Low risk & $\begin{array}{l}\text { Timing performed by a member of the research team with a stopwatch. No ad- } \\
\text { ditional information }\end{array}$ \\
\hline
\end{tabular}

\begin{tabular}{lll}
\hline $\begin{array}{l}\text { Blinding of outcome as- } \\
\text { sessment (detection bias) } \\
\text { Vocal cord view score }\end{array}$ & High risk & Not feasible because of the nature of the intervention \\
\hline $\begin{array}{l}\text { Blinding of outcome as- } \\
\text { sessment (detection bias) } \\
\text { Advserse haemodynamic }\end{array}$ & Unclear risk & $\begin{array}{l}\text { Timing performed by a member of the research team with a stopwatch. No ad- } \\
\text { ditional information }\end{array}$
\end{tabular}

Advserse haemodynamic

response to endotracheal intubation

\begin{tabular}{lll}
\hline $\begin{array}{l}\text { Blinding of outcome as- } \\
\text { sessment (detection bias) } \\
\begin{array}{l}\text { All other adverse effects } \\
\text { of intubation }\end{array}\end{array}$ & Unclear risk & $\begin{array}{l}\text { Timing performed by a member of the research team with a stopwatch. No ad- } \\
\text { ditional information }\end{array}$ \\
\hline $\begin{array}{l}\text { Blinding of outcome as- } \\
\text { sessment (detection bias) } \\
\text { All outcomes }\end{array}$ & Unclear risk & $\begin{array}{l}\text { Timing performed by a member of the research team with a stopwatch. No ad- } \\
\text { ditional information }\end{array}$ \\
\hline $\begin{array}{l}\text { Incomplete outcome data } \\
\text { (attrition bias) } \\
\text { All outcomes }\end{array}$ & Unclear risk & $\begin{array}{l}\text { Of } 50 \text { children recruited, 1 participant in the AT group was removed from the } \\
\text { study before intubation because of an unanticipated last minute change in the } \\
\text { airway management plan }\end{array}$ \\
\hline
\end{tabular}


Vlatten 2012 (Continued)
Selective reporting (re-
Low risk
All outcomes prespecified in Methods reported porting bias)

White 2012

\begin{tabular}{ll}
\hline Methods & Randomized controlled trial \\
\hline Participants & $\begin{array}{l}\text { A total of } 60 \text { healthy children (20 infants and } 40 \text { children) of ASA physical status I or II scheduled for } \\
\text { elective surgery requiring tracheal intubation. Exclusion criteria were inability of parents to understand } \\
\text { the study or consent process and previous or anticipated airway problems in children }\end{array}$ \\
\hline Interventions & $\begin{array}{l}\text { Comparison of Airtraq optical laryngoscope vs conventional laryngoscope. Anaesthesia was induced } \\
\text { via an intravenous technique (propofol } \pm \text { fentanyl titrated to effect) or an inhalational technique } \\
\text { (sevoflurane in oxygen } \pm \text { nitrous oxide) }\end{array}$ \\
& $\begin{array}{l}\text { Neuromuscular blocking agent administered, with choice made at the discretion of the consultant } \\
\text { anaesthetist. Technique and size of Airtraq used were in accordance with manufacturer's instructions }\end{array}$ \\
\hline Outcomes & $\begin{array}{l}\text { Primary outcome measure was time taken to successful tracheal intubation. Secondary outcome mea- } \\
\text { sures were percentage of glottic opening (POGO) score, visual analogue score (VAS) for field of view and } \\
\text { ease of use, and evidence of traumatic intubation }\end{array}$ \\
\hline Notes & $\begin{array}{l}\text { All investigators were consultant paediatric anaesthetists who had used the Airtraq on at least } 10 \text { occa- } \\
\text { sions before conducting the study }\end{array}$ \\
Study was done at 2 UK centres. The Airtraq devices used in this study were donated free of charge by \\
the manufacturers, who had no further involvement in the study. This study was supported in part by \\
a grant (project number 228) from the David Telling Foundation, for which the study authors are very \\
grateful. No competing interests declared
\end{tabular}

\section{Risk of bias}

\begin{tabular}{|c|c|c|}
\hline Bias & Authors' judgement & Support for judgement \\
\hline $\begin{array}{l}\text { Blinding of participants } \\
\text { and personnel (perfor- } \\
\text { mance bias) }\end{array}$ & High risk & Not feasible because of the nature of the intervention \\
\hline $\begin{array}{l}\text { Allocation concealment } \\
\text { (selection bias) }\end{array}$ & Unclear risk & $\begin{array}{l}\text { Randomization via a stratified blocked design by age group. No additional in- } \\
\text { formation }\end{array}$ \\
\hline $\begin{array}{l}\text { Random sequence genera- } \\
\text { tion (selection bias) }\end{array}$ & Low risk & Randomization via a stratified blocked design by age group \\
\hline $\begin{array}{l}\text { Blinding of outcome as- } \\
\text { sessment (detection bias) } \\
\text { The number of attempts } \\
\text { at intubation }\end{array}$ & High risk & Not feasible because of the nature of the intervention \\
\hline $\begin{array}{l}\text { Blinding of outcome as- } \\
\text { sessment (detection bias) } \\
\text { Time to intubate }\end{array}$ & Unclear risk & No information given \\
\hline $\begin{array}{l}\text { Blinding of outcome as- } \\
\text { sessment (detection bias) } \\
\text { Vocal cord view score }\end{array}$ & High risk & Not feasible because of the nature of the intervention \\
\hline
\end{tabular}


White 2012 (Continued)
Blinding of outcome as-
This outcome not measured in this study sessment (detection bias) Advserse haemodynamic response to endotracheal intubation

\begin{tabular}{|c|c|c|}
\hline $\begin{array}{l}\text { Blinding of outcome as- } \\
\text { sessment (detection bias) } \\
\text { All other adverse effects } \\
\text { of intubation }\end{array}$ & Unclear risk & No information given \\
\hline $\begin{array}{l}\text { Blinding of outcome as- } \\
\text { sessment (detection bias) } \\
\text { All outcomes }\end{array}$ & Unclear risk & No information given \\
\hline $\begin{array}{l}\text { Incomplete outcome data } \\
\text { (attrition bias) } \\
\text { All outcomes }\end{array}$ & Low risk & Results of all randomized children presented \\
\hline $\begin{array}{l}\text { Selective reporting (re- } \\
\text { porting bias) }\end{array}$ & Low risk & All outcomes prespecified in Methods reported \\
\hline
\end{tabular}

List of acronyms and abbreviations:

ASA: American Society of Anesthesiologists; BURP: backward-upward-rightward pressure of the larynx; CL: Cormack-Lehane score; C\&L: Cormack-Lehane score; DL: direct laryngoscope; TruView EVO2: type of videolaryngoscope; GS: GlideScope; GV: GlideScope videolaryngoscope; IDS: Intubation Difficulty Scale; kg: kilogram; mg: milligram; min: minute; n: total number; NTT: nasotracheal tube; POGO: percentage of glottic opening; STORZ: type of videolaryngoscope; TTBV: time to best view; TTI: time to intubation; $\mu$ g: microgram; VAS: visual analogue scale; VL: videolaryngoscope; vol: volume

\section{Characteristics of excluded studies [ordered by study ID]}

\begin{tabular}{ll}
\hline Study & Reason for exclusion \\
\hline Riveros 2013 & Included neonates to 10 years of age \\
\hline Singh 2009 & Included infants and neonates \\
\hline Tutuncu 2011 & $\begin{array}{l}\text { Participants allocated according to hospital protocol last number (odd numbers - Truview laryngo- } \\
\text { scope; even numbers - Macintosh laryngoscope); non-RCT }\end{array}$ \\
\hline
\end{tabular}

RCT: randomized controlled trial

Characteristics of studies awaiting assessment [ordered by study ID]

\section{Cakirca 2016}

\begin{tabular}{ll}
\hline Methods & Cases were randomly allocated to 3 groups for type of intubation to be applied \\
\hline Participants & $\begin{array}{l}\text { Study included } 90 \text { paediatric patients } 4 \text { to } 10 \text { years of age who were to undergo endotracheal intu- } \\
\text { bation for surgery }\end{array}$ \\
\hline Interventions & $\begin{array}{l}\text { Group } 1(n=30) \text { Macintosh laryngoscope, Group } 2(n=30) \text { TruView EVO 2, and Group } 3(n=30) \text { Mc- } \\
\text { Grath videolaryngoscope }\end{array}$
\end{tabular}

Outcomes
Mallampati and Cormack Lehane scores, EtCO2, SpO2, and haemodynamic values were recorded. Time to intubation (time from entry of the laryngoscope the mouth until tube is seen to have 
Cakirca 2016 (Continued)

passed the vocal cords), number of attempts made for intubation, percentage of glottic opening seen with the laryngoscope, and Intubation Difficulty Scale scores were recorded

Notes Study will be addressed in the review update

\section{Patil 2016}

\begin{tabular}{ll}
\hline Methods & Prospective randomized controlled trial \\
\hline Participants & $\begin{array}{l}60 \text { patients of either sex, } 8 \text { to } 18 \text { years of age, belonging to American Society of Anesthesiologists } \\
\text { physical status I or II and Mallampati grade I or II were included }\end{array}$ \\
\hline Interventions & $\begin{array}{l}\text { Participants in Group } 1 \text { underwent conventional laryngoscopy with Macintosh direct laryngoscope } \\
\text { and those in Group } 2 \text { underwent videolaryngoscopy with Storz C-MAC VL for nasal intubation }\end{array}$ \\
\hline Outcomes & $\begin{array}{l}\text { C-L grading, time required for intubation, need for additional manoeuvres, and haemodynamic } \\
\text { changes during and after intubation were compared between groups }\end{array}$ \\
\hline Notes & Study will be addressed in the review update \\
\hline
\end{tabular}

Vadi 2016

\begin{tabular}{ll}
\hline Methods & Single-centre prospective randomized non-blinded parallel-group study \\
\hline Participants & $\begin{array}{l}93 \text { children younger than } 2 \text { years of age scheduled for elective surgery requiring tracheal intubation } \\
\text { at our tertiary care hospital in the United States between October 2012 and May 2013. Younger chil- } \\
\text { dren underwent laryngoscopy with manual in-line stabilization }\end{array}$ \\
\hline Interventions & $\begin{array}{l}\text { Participants were randomly assigned to undergo intubation via GlideScope Cobalt videolaryn- } \\
\text { goscopy (size } 2 \text { blade; GlideScope), Storz DCI videolaryngoscopy (Miller } 1 \text { video blade; Storz), or di- } \\
\text { rect laryngoscopy (Miller } 1 \text { blade; DL) }\end{array}$ \\
\hline Outcomes & $\begin{array}{l}\text { Total time to successful intubation (TTSI), best glottic view, and maximum degrees of neck devia- } \\
\text { tion were recorded }\end{array}$ \\
\hline Notes & Study will be addressed in the review update \\
\hline
\end{tabular}

$\mathrm{C}-\mathrm{L}$ grading: Cormack-Lehane grading; $\mathrm{EtCO}_{2}$ : end-tidal carbon dioxide; GlideScope Cobalt: type of videolaryngoscope; $\mathrm{McGrath}$ : type of videolaryngoscope; Miller: type of direct laryngoscope; Storz C-MAC VL: type of videolaryngoscope; TruView EVO2: type of videolaryngoscope

Characteristics of ongoing studies [ordered by study ID]

Jamil 2015

Trial name or title

Methods
A Comparative Evaluation of Airtraq Optical Laryngoscope ${ }^{\mathrm{TM}}$ and Miller Blade in Pediatric Patients Undergoing Elective Surgery Requiring Tracheal Intubation

Investigators compared the efficacy of Airtraq vs the Miller laryngoscope as intubation devices in paediatric patients. This prospective randomized study was conducted at a tertiary care teaching hospital 
Jamil 2015 (Continued)

Participants

A total of 60 ASA grade I-II paediatric patients 2 to 10 years of age, posted for routine surgery requiring tracheal intubation, were randomly allocated to undergo intubation with a Miller $(n=30)$ or Air$\operatorname{traq}(\mathrm{n}=30)$ laryngoscope

\begin{tabular}{ll}
\hline Interventions & Intubation with Airtraq Optical Laryngoscope ${ }^{\mathrm{TM}}$ and Miller Blade \\
\hline Outcomes & $\begin{array}{l}\text { Primary outcome measures were time of intubation, ease of intubation, number of attempts and } \\
\text { POGO score, haemodynamic changes, and airway trauma }\end{array}$ \\
\hline Starting date & May 2013 \\
\hline Contact information & Shahin N Jamil, JN Medical College, Aligarh Muslim University \\
\hline Notes & May 2014 (final data collection date for primary outcome measure) \\
\hline
\end{tabular}

Kim 2016

\begin{tabular}{ll}
\hline Trial name or title & $\begin{array}{l}\text { A Comparison of McGrath MAC Videolaryngoscopy and Macintosh Laryngoscopy for Orotracheal In- } \\
\text { tubation in Children }\end{array}$ \\
\hline Methods & Randomised controlled double-blind study \\
\hline Participants & Children 1 year to 10 years of age \\
\hline Interventions & McGrath MAC videolaryngoscopy \\
\hline Outcomes & Intubation time, Cormack and Lehane grade \\
\hline Starting date & July 2016 \\
\hline Contact information & $\begin{array}{l}\text { Ji Eun Kim, Ajou University School of Medicine, Department of Anesthesiology and Pain Medicine, } \\
\text { Ajou University School of Medicine, Suwon, Seoum, Korea, Republic of }\end{array}$ \\
\hline Notes & September 2016 (final data collection date for primary outcome measure) \\
\hline
\end{tabular}

Airtraq Optical Laryngoscope: type of videolaryngoscope; ASA: American Society of Anesthesiologists; GlideScope: type of videolaryngoscope; McGrath MAC: type of videolaryngoscope; $n$ : total number; POGO: percentage of glottic opening; Storz DCI: type of videolaryngoscope

\section{DATA AND ANALYSES}

\section{Comparison 1. Indirect videolaryngoscope vs conventional laryngoscope for intubation of children}

\begin{tabular}{lllll}
\hline Outcome or subgroup title & No. of studies & $\begin{array}{l}\text { No. of partici- } \\
\text { pants }\end{array}$ & Statistical method & Effect size \\
\hline $\begin{array}{l}1 \text { Unsuccessful or more than 2 intuba- } \\
\text { tion attempts }\end{array}$ & 12 & 798 & $\begin{array}{l}\text { Mean Difference (IV, Ran- } \\
\text { dom, 95\% Cl) }\end{array}$ & $5.49[1.37,9.60]$ \\
\hline $\begin{array}{llll}1.1 \text { Other videolaryngoscopes } \\
\end{array}$ & 4 & 202 & $\begin{array}{l}\text { Mean Difference (IV, Ran- } \\
\text { dom, 95\% Cl) }\end{array}$ & $\begin{array}{l}11.04[4.62, \\
17.46]\end{array}$ \\
\hline
\end{tabular}




\begin{tabular}{|c|c|c|c|c|}
\hline Outcome or subgroup title & No. of studies & $\begin{array}{l}\text { No. of partici- } \\
\text { pants }\end{array}$ & Statistical method & Effect size \\
\hline 1.2 GlideScope videolaryngoscope & 4 & 403 & $\begin{array}{l}\text { Mean Difference (IV, Ran- } \\
\text { dom, } 95 \% \mathrm{CI} \text { ) }\end{array}$ & $5.12[0.45,9.80]$ \\
\hline 1.3 Airtraq videolaryngoscope & 4 & 193 & $\begin{array}{l}\text { Mean Difference (IV, Ran- } \\
\text { dom, } 95 \% \mathrm{CI} \text { ) }\end{array}$ & $\begin{array}{l}-0.81[-16.59 \\
14.96]\end{array}$ \\
\hline $\begin{array}{l}2 \text { Intubation time -simulated difficult } \\
\text { airway scenario study excluded }\end{array}$ & 11 & 758 & $\begin{array}{l}\text { Mean Difference (IV, Ran- } \\
\text { dom, } 95 \% \mathrm{CI} \text { ) }\end{array}$ & $4.20[0.74,7.66]$ \\
\hline $\begin{array}{l}3 \text { Intubation time - nasal intubation } \\
\text { study excluded }\end{array}$ & 11 & 718 & $\begin{array}{l}\text { Mean Difference (IV, Ran- } \\
\text { dom, } 95 \% \mathrm{CI} \text { ) }\end{array}$ & $5.43[1.06,9.80]$ \\
\hline 4 Successful first intubation attempts & 11 & 749 & $\begin{array}{l}\text { Risk Ratio (M-H, Random, } \\
95 \% \mathrm{Cl})\end{array}$ & $0.96[0.91,1.02]$ \\
\hline $\begin{array}{l}5 \text { Unsuccessful or more than } 2 \text { intuba- } \\
\text { tion attempts }\end{array}$ & 5 & 263 & $\begin{array}{l}\text { Risk Ratio (M-H, Random, } \\
95 \% \mathrm{Cl})\end{array}$ & $4.93[1.33,18.31]$ \\
\hline $\begin{array}{l}6 \text { Vocal cords score: laryngoscopic view } \\
\text { according to the Cormack and Lehane } \\
\text { grade (C\&L grade) - grade } 1 \text { view }\end{array}$ & 3 & 190 & $\begin{array}{l}\text { Risk Ratio (M-H, Random, } \\
95 \% \mathrm{Cl})\end{array}$ & $1.06[0.93,1.21]$ \\
\hline
\end{tabular}

Analysis 1.1. Comparison 1 Indirect videolaryngoscope vs conventional laryngoscope for intubation of children, Outcome 1 Unsuccessful or more than 2 intubation attempts.

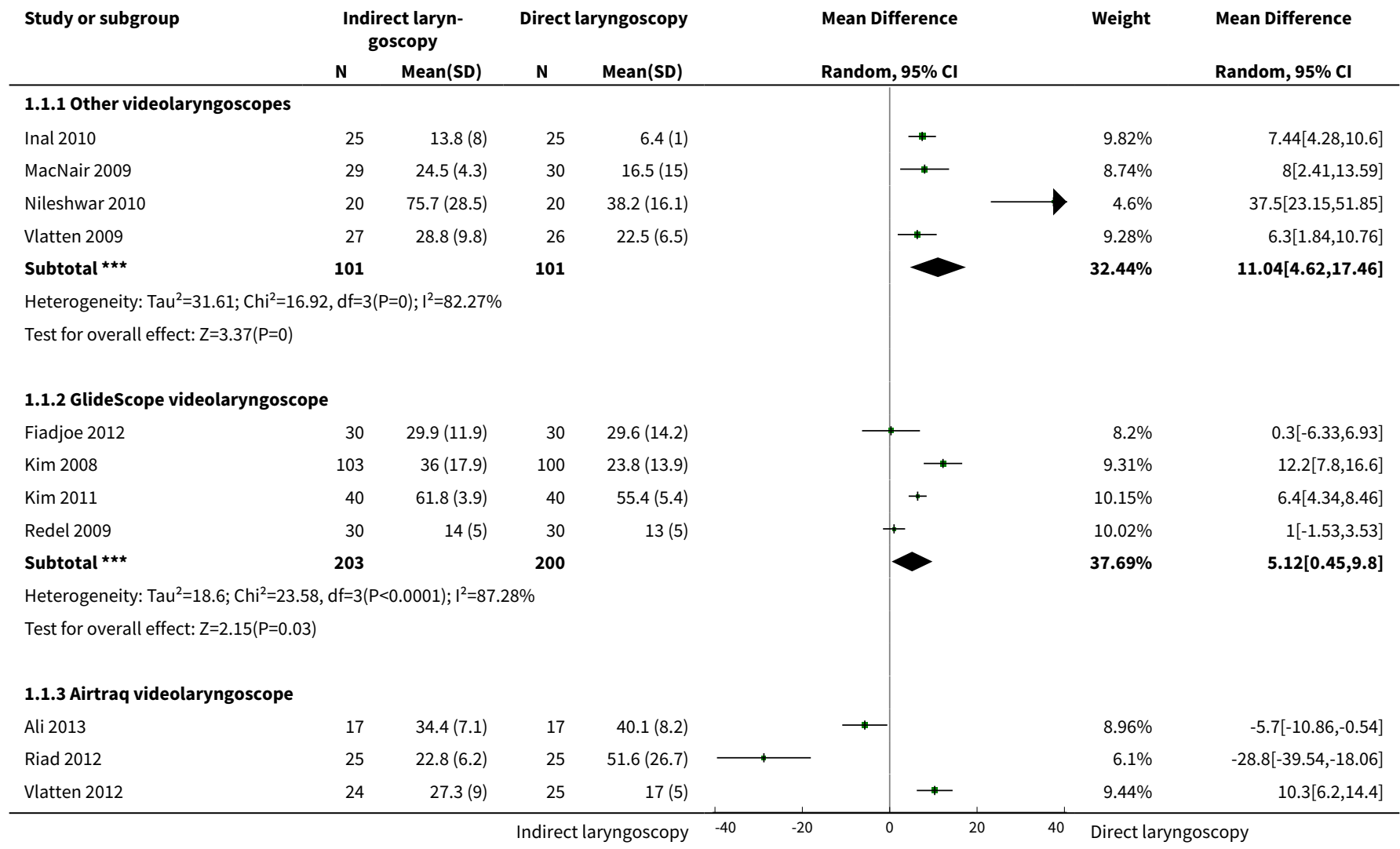




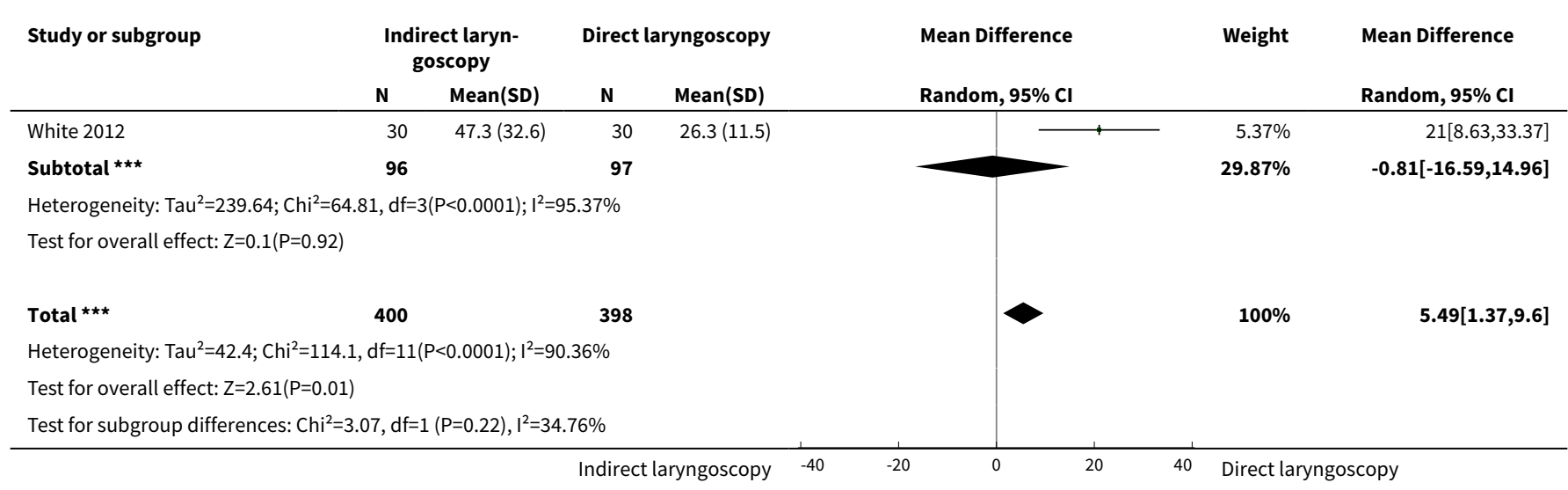

Analysis 1.2. Comparison 1 Indirect videolaryngoscope vs conventional laryngoscope for intubation of children, Outcome 2 Intubation time -simulated difficult airway scenario study excluded.

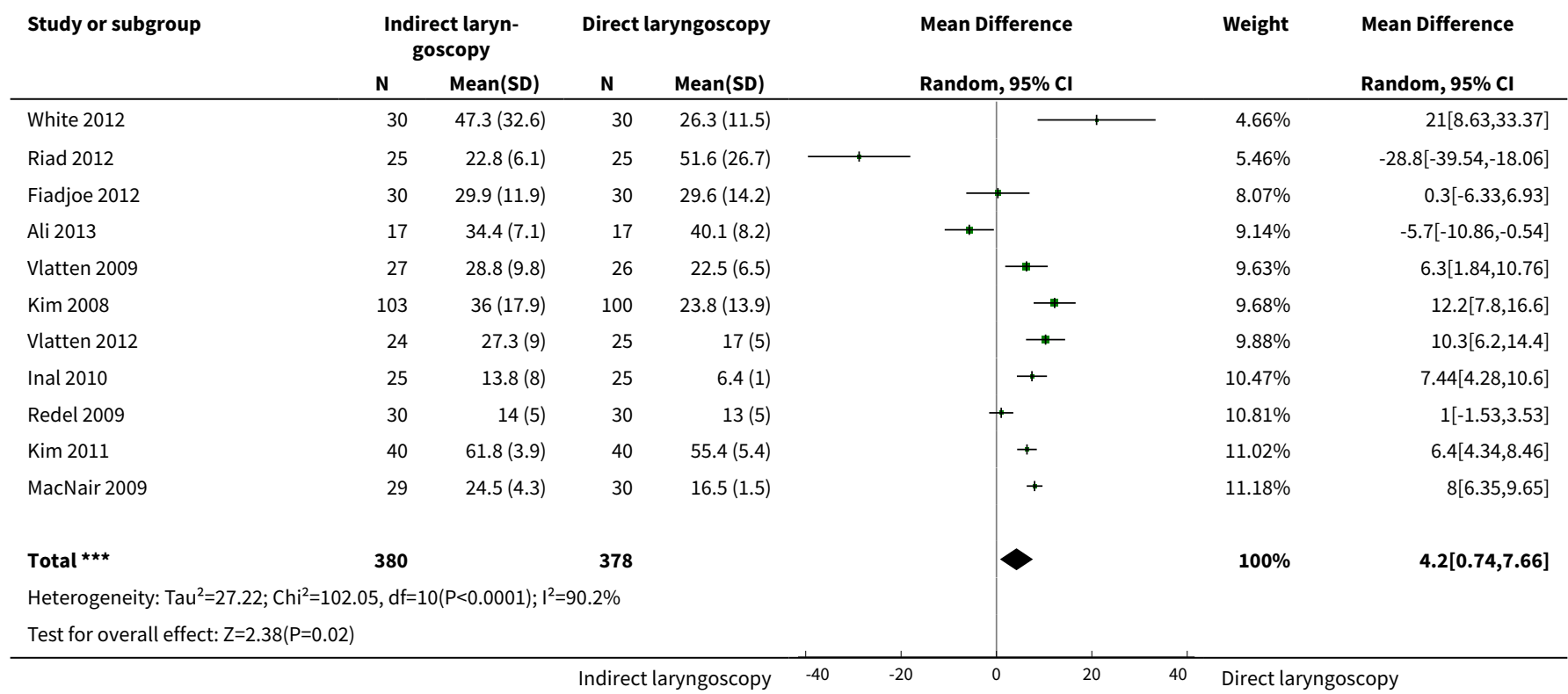

Analysis 1.3. Comparison 1 Indirect videolaryngoscope vs conventional laryngoscope for intubation of children, Outcome 3 Intubation time - nasal intubation study excluded.

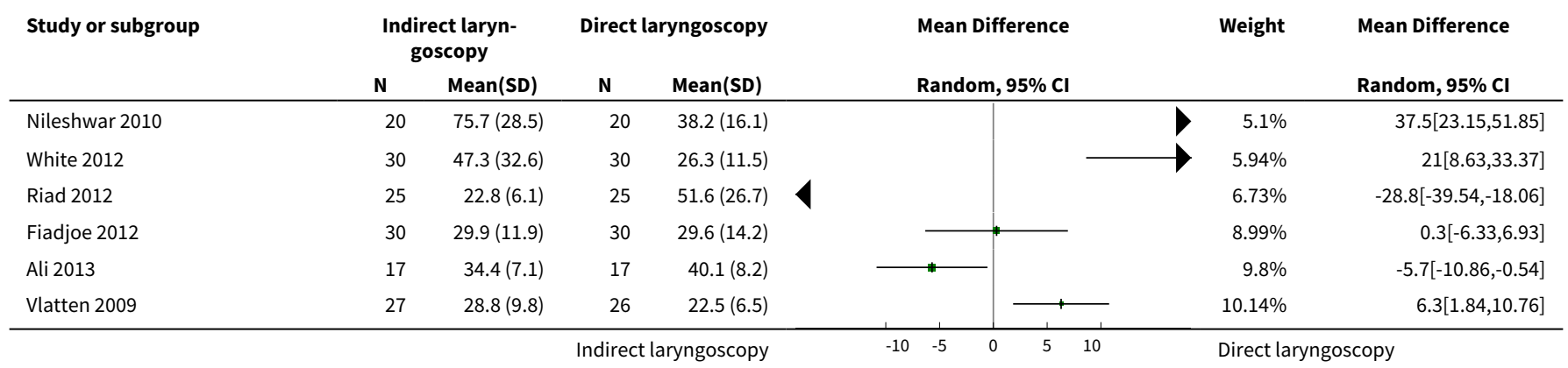




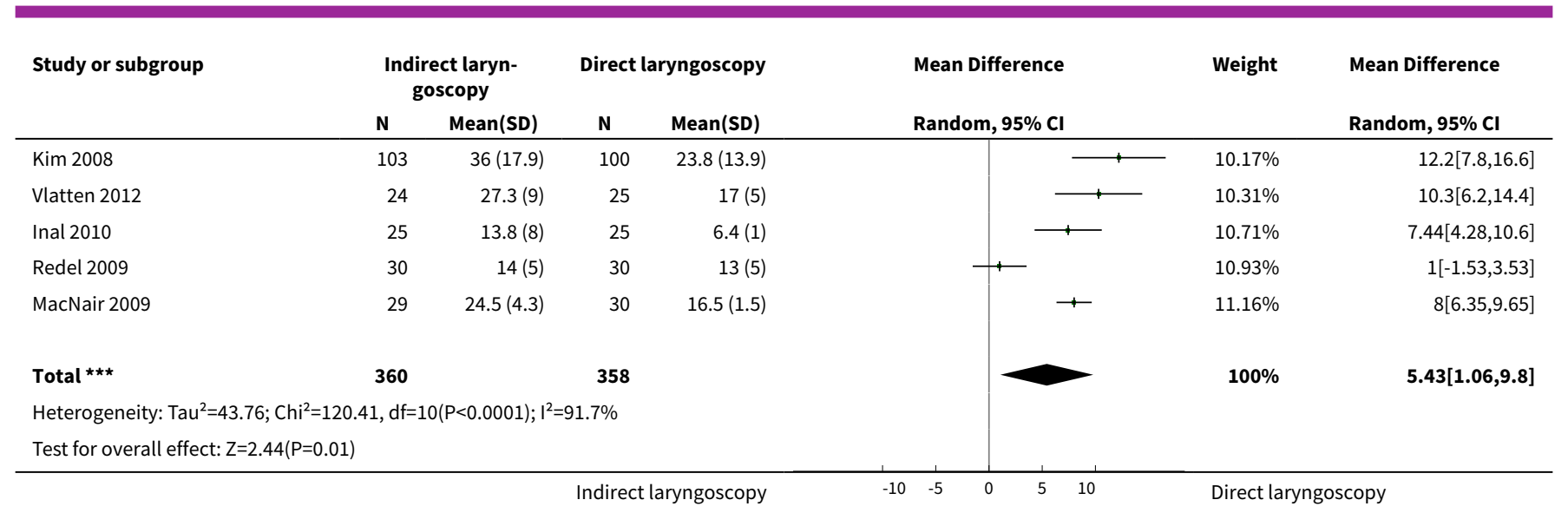

Analysis 1.4. Comparison 1 Indirect videolaryngoscope vs conventional laryngoscope for intubation of children, Outcome 4 Successful first intubation attempts.

\begin{tabular}{|c|c|c|c|c|c|}
\hline Study or subgroup & $\begin{array}{l}\text { Indirect laryn- } \\
\text { goscopy } \\
n / N\end{array}$ & $\begin{array}{l}\text { Direct laryn- } \\
\text { goscopy } \\
n / N\end{array}$ & $\begin{array}{c}\text { Risk Ratio } \\
\text { M-H, Random, } 95 \% \mathrm{Cl}\end{array}$ & Weight & $\begin{array}{l}\text { Risk Ratio } \\
\text { Random, } 95 \% \mathrm{Cl} \\
\end{array}$ \\
\hline Nileshwar 2010 & $11 / 20$ & $20 / 20$ & - & $1.71 \%$ & $0.56[0.38,0.83]$ \\
\hline Ali 2013 & $16 / 17$ & $13 / 17$ & & $2.92 \%$ & $1.23[0.92,1.64]$ \\
\hline Vlatten 2012 & $20 / 24$ & $25 / 25$ & 1 & $5.4 \%$ & $0.84[0.69,1.01]$ \\
\hline MacNair 2009 & $25 / 30$ & $30 / 30$ & & $6.3 \%$ & $0.84[0.71,0.99]$ \\
\hline Kim 2011 & $37 / 40$ & $40 / 40$ & . & $10.5 \%$ & $0.93[0.84,1.02]$ \\
\hline Inal 2010 & $25 / 25$ & $25 / 25$ & - & $12.27 \%$ & $1[0.93,1.08]$ \\
\hline Kim 2008 & $93 / 103$ & $97 / 100$ & $\longrightarrow$ & $12.58 \%$ & $0.93[0.87,1]$ \\
\hline Vlatten 2009 & $27 / 27$ & $26 / 26$ & $\longrightarrow$ & $12.59 \%$ & $1[0.93,1.07]$ \\
\hline Redel 2009 & $30 / 30$ & $30 / 30$ & $\longrightarrow$ & $13.22 \%$ & $1[0.94,1.07]$ \\
\hline White 2012 & $30 / 30$ & $30 / 30$ & $\longrightarrow$ & $13.22 \%$ & $1[0.94,1.07]$ \\
\hline Total $(95 \% \mathrm{CI})$ & 376 & 373 & & $100 \%$ & $0.96[0.91,1.02]$ \\
\hline \multicolumn{6}{|c|}{ Total events: 343 (Indirect laryngoscopy), 364 (Direct laryngoscopy) } \\
\hline \multicolumn{6}{|c|}{ Heterogeneity: $\mathrm{Tau}^{2}=0 ; \mathrm{Chi}^{2}=30.67, \mathrm{df}=10(\mathrm{P}=0) ; \mathrm{I}^{2}=67.39 \%$} \\
\hline Test for overall effect & & & & & \\
\hline
\end{tabular}

Analysis 1.5. Comparison 1 Indirect videolaryngoscope vs conventional laryngoscope for intubation of children, Outcome 5 Unsuccessful or more than $\mathbf{2}$ intubation attempts.

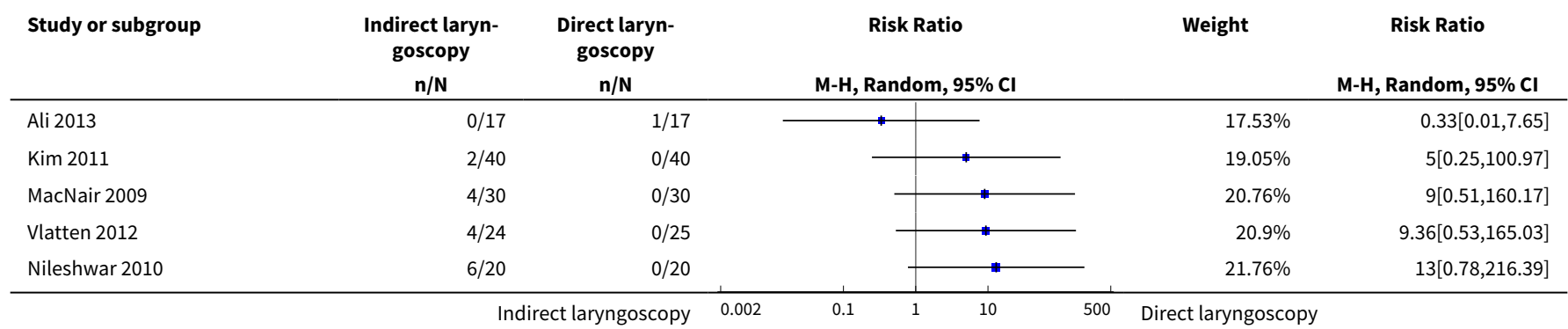




$\begin{aligned} & \text { Indirect laryn- } \\ & \text { goscopy } \\ & \mathbf{n} / \mathbf{N}\end{aligned}$
$\begin{aligned} & \text { Study or subgroup } \\ & \text { goscopy } \\ & \mathbf{n} / \mathbf{N}\end{aligned}$

$\begin{array}{lllllll}\text { Indirect laryngoscopy } & 0.002 & 0.1 & 1 & 10 & 500 & \text { Direct laryngoscopy }\end{array}$

Analysis 1.6. Comparison 1 Indirect videolaryngoscope vs conventional laryngoscope for intubation of children, Outcome 6 Vocal cords score: laryngoscopic view according to the Cormack and Lehane grade (C\&L grade) - grade 1 view.

\begin{tabular}{|c|c|c|c|c|c|}
\hline Study or subgroup & $\begin{array}{l}\text { Indirect laryn- } \\
\text { goscopy } \\
n / N \\
\end{array}$ & $\begin{array}{l}\text { Direct laryn- } \\
\text { goscopy } \\
n / N\end{array}$ & $\begin{array}{c}\text { Risk Ratio } \\
\text { M-H, Random, } 95 \% \mathrm{CI}\end{array}$ & Weight & $\begin{array}{c}\text { Risk Ratio } \\
\text { M-H, Random, } 95 \% \mathrm{CI}\end{array}$ \\
\hline Inal 2010 & $23 / 25$ & $17 / 25$ & & $14.87 \%$ & $1.35[1.01,1.81]$ \\
\hline Kim 2011 & $37 / 40$ & $37 / 40$ & & $38.72 \%$ & $1[0.88,1.13]$ \\
\hline Redel 2009 & $30 / 30$ & $29 / 30$ & & $46.41 \%$ & $1.03[0.94,1.13]$ \\
\hline \multicolumn{6}{|c|}{ Total events: 90 (Indirect laryngoscopy), 83 (Direct laryngoscopy) } \\
\hline \multicolumn{6}{|c|}{ Heterogeneity: $\mathrm{Tau}^{2}=0.01 ; \mathrm{Chi}^{2}=4.83, \mathrm{df}=2(\mathrm{P}=0.09) ; \mathrm{I}^{2}=58.59 \%$} \\
\hline Test for overall effect & & & & & \\
\hline
\end{tabular}

\section{APPENDICES}

\section{Appendix 1. CENTRAL (the Cochrane Library) search strategy}

\#1 MeSH descriptor: [Laryngoscopy] explode all trees

\#2 MeSH descriptor: [Laryngoscopes] explode all trees

\#3 (video* near laryngoscop*) or laryngoscop*:ti,ab

$\# 4 \# 1$ or \#2 or \#3

\#5 MeSH descriptor: [Intubation, Intratracheal] explode all trees

\#6 (intubat* near ?tracheal) or intubat*:ti,ab

$\# 7$ \#5 or \#6

\#8 (\#4 and \#7) not (adult* not (child and adult $\left.\left.{ }^{\star}\right)\right)$

\section{Appendix 2. MEDLINE (Ovid SP) search strategy}

1. exp Laryngoscopy/ or exp Laryngoscopes/ or (video* adj3 laryngoscop*).af. or laryngoscop*.ti,ab.

2. exp Intubation, Intratracheal/ or (intubat* adj3 ?tracheal).mp. or intubat*.ti,ab.

3. (1 and 2) not (adult* not (child and adult*)).af. 
4. ((randomized controlled trial or controlled clinical trial).pt. or randomized.ab. or placebo.ab. or clinical trials as topic.sh. or randomly.ab. or trial.ti.) not (animals not (humans and animals)).sh.

5.3 and 4

\section{Appendix 3. Embase (Ovid SP) search strategy}

1. exp laryngoscopy/ or exp laryngoscope/ or (video* adj3 laryngoscop^).af. or laryngoscop*.ti,ab.

2. exp endotracheal intubation/ or (intubat* adj3 ?tracheal).mp. or intubat ${ }^{\star} . t i, a b$.

3. (1 and 2) not (adult* not (child and adult*)).af.

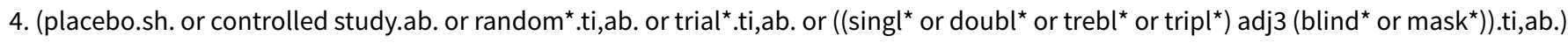
not (animals not (humans and animals)).sh.

5.3 and 4

\section{Appendix 4. CINAHL (EBSCOhost) search strategy}

S1 (MM "Laryngoscopy") OR TX (video* N3 laryngoscop*) OR TI laryngoscop* OR AB laryngoscop*

S2 (MM "Intubation, Intratracheal") OR TX (intubat* N3 ?tracheal) OR TI intubat* OR AB intubat*)

S3 (S1 and S2) NOT (adult* not (child and adult*))

S4 random ${ }^{\star}$ or placebo ${ }^{\star}$ or prospective* or (trial ${ }^{\star} \mathrm{N} 3$ (control* or clinical)) or multicenter ${ }^{\star}$ or ((blind ${ }^{\star}$ or mask $^{\star}$ ) and (single or double or triple or treble))

S5 S3 AND S4

Appendix 5. Data extraction form

Data collection form

\section{Review title or ID}

Study ID (surname of first author and year first full report of study was published (e.g. Smith 2001)

Report IDs of other reports of this study (e.g. duplicate publications, follow-up studies)

\section{Notes:}




\section{General information}

Date form completed (dd/mm/yyyy)

\section{Name/ID of person extracting data}

\section{Report title}

(title of paper/abstract/report from which data are extracted)

\section{Report ID}

(ID for this paper/abstract/report)

\section{Reference details}

\section{Report author contact details}

\section{Publication type}

(e.g. full report, abstract, letter)

\section{Study funding sources}

(including role of funders)

\section{Possible conflicts of interest}

(for study authors)

\section{Notes:}

\section{Study eligibility}

\begin{tabular}{|c|c|c|c|c|c|}
\hline Study characteristics & $\begin{array}{l}\text { Eligibility criteria } \\
\text { (Insert eligibility criteria for each charac- } \\
\text { teristic as defined in the Protocol) }\end{array}$ & Yes & No & Unclear & $\begin{array}{l}\text { Location in } \\
\text { text } \\
\text { (pg\& \&/fig/ } \\
\text { table) }\end{array}$ \\
\hline Type of study & Randomized controlled trial & & & & \\
\hline
\end{tabular}

\section{Participants}

\section{Types of interventions}

\section{Types of outcome measures}

INCLUDE EXCLUDE

\section{Reason for exclusion}


(Continued)

Notes:

DO NOT PROCEED IF STUDY EXCLUDED FROM REVIEW

\section{Population and setting}

\section{Description}

Include comparative information for each group (i.e. intervention and controls) if available
Location in text

(pg \& $/ /$ fig/table)

\section{Population description}

(from which study participants are drawn)

\section{Setting}

(including location and social context)

\section{Inclusion criteria}

\section{Exclusion criteria}

\section{Method/s of recruitment of participants}

Informed consent obtained Yes No Unclear

\section{Notes:}

4. Methods

Descriptions as stated in report/paper

Location in text

(pg \& $\mathbf{q} /$ fig/table)

\begin{tabular}{l}
\hline Aim of study \\
\hline Design (e.g. parallel, cross-over, cluster) \\
\hline Unit of allocation \\
(by individuals, clusters/groups, or body parts)
\end{tabular}

\section{Start date}

\section{End date}

\section{Total study duration}

\section{Ethical approval needed/obtained for study}

Yes No Unclear 


\section{Risk of bias assessment}

\begin{tabular}{|c|c|c|c|c|c|}
\hline \multirow[t]{2}{*}{ Domain } & \multicolumn{3}{|c|}{ Risk of bias } & \multirow{2}{*}{$\begin{array}{l}\text { Support for } \\
\text { judgement }\end{array}$} & \multirow{2}{*}{$\begin{array}{l}\text { Location in } \\
\text { text } \\
(p g \& \Psi / f i g / t a \\
b(e)\end{array}$} \\
\hline & Low risk & High risk & Unclear risk & & \\
\hline
\end{tabular}

\section{Random sequence generation}

(selection bias)

\section{Allocation concealment}

(selection bias)

\begin{tabular}{|c|c|}
\hline $\begin{array}{l}\text { Blinding of participants and personnel } \\
\text { (performance bias) }\end{array}$ & $\begin{array}{l}\text { Outcome } \\
\text { group: All/ }\end{array}$ \\
\hline (if required) & $\begin{array}{l}\text { Outcome } \\
\text { group: }\end{array}$ \\
\hline
\end{tabular}

\section{Blinding of outcome assessment}

(detection bias)

\section{Outcome}

group: All/

$\begin{array}{ll}\text { (if required) } & \text { Outcome } \\ & \text { group: }\end{array}$

\section{Incomplete outcome data}

(attrition bias)

\section{Selective outcome reporting?}

(reporting bias)

\section{Other bias}

\section{Notes:}

\section{Participants}

Provide overall data and, if available, comparative data for each intervention or comparison group.

\begin{tabular}{|c|c|c|}
\hline & $\begin{array}{l}\text { Description as stated } \\
\text { in report/paper }\end{array}$ & $\begin{array}{l}\text { Location in text } \\
\text { (pg \& } \uparrow / \text { fig/table) }\end{array}$ \\
\hline Total no. randomized & & \\
\hline
\end{tabular}


(Continued)

(or total pop. at start of study for NRCTS)

\section{Clusters}

(if applicable, no., type, no. people per cluster)

\section{Baseline imbalances}

\section{Withdrawals and exclusions}

(if not provided below by outcome)

Age

\section{Race/Ethnicity}

\section{Severity of illness}

\section{Comorbidities}

Other treatment received (additional to study intervention)

\section{Other relevant sociodemographics}

\section{Subgroups measured}

\section{Subgroups reported}

\section{Notes:}

\section{Intervention groups}

Intervention group 1

\section{Group name}

\section{No. randomized to group}

(specify whether no. people or clusters)

Theoretical basis (include key references)

Description (include sufficient detail for replication, e.g. content, dose, components)

\section{Duration of treatment period}

Timing (e.g. frequency, duration of each episode) 
(Continued)

Delivery (e.g. mechanism, medium, intensity, fidelity)

\section{Providers}

(e.g. no., profession, training, ethnicity, etc., if relevant)

\section{Co-interventions}

\section{Economic variables}

(i.e. intervention cost, changes in other costs as result of intervention)

\section{Resource requirements to replicate intervention}

(e.g. staff numbers, cold chain, equipment)

\section{Notes:}

\section{Outcomes}

Copy and paste table for each outcome.

\section{Outcome 1}

\section{Outcome name}

\section{Time points measured}

\section{Time points reported}

Outcome definition (with diagnostic criteria if relevant)

\section{Person measuring/reporting}

\section{Unit of measurement}

(if relevant)

Scales: upper and lower limits (indicate whether high or low score is good)

Is outcome/tool validated? Yes No Unclear

\section{Imputation of missing data}

(e.g. assumptions made for ITT analysis)

\section{Assumed risk estimate}

(e.g. baseline or population risk noted in Background)

\section{Power}




\section{Results}

Copy and paste the appropriate table for each outcome, including additional tables for each time point and subgroup as required.

\section{Dichotomous outcome}

Description as stated in report/paper

Location in

\section{Comparison}

\section{Outcome}

\section{Subgroup}

\section{Time point}

(specify whether from start or end of intervention)

\begin{tabular}{|c|c|c|c|c|}
\hline \multirow[t]{2}{*}{ Results } & \multicolumn{2}{|c|}{ Intervention } & \multicolumn{2}{|c|}{ Comparison } \\
\hline & No. events & No. participants & No. events & $\begin{array}{l}\text { No. partici- } \\
\text { pants }\end{array}$ \\
\hline
\end{tabular}

\section{No. missing participants and reasons}

\section{No. participants moved from other} group and reasons

\section{Any other results reported}

Unit of analysis (by individuals, clus-

ter/groups, or body parts)

Statistical methods used and appropri-

ateness of these methods (e.g. adjust-

ment for correlation)

\begin{tabular}{ll}
\hline Reanalysis required? (specify) & Yes No Unclear \\
\hline Reanalysis possible? & Yes No Unclear \\
\hline
\end{tabular}

\section{Reanalysed results}

\section{Notes:}




\section{Continuous outcome}




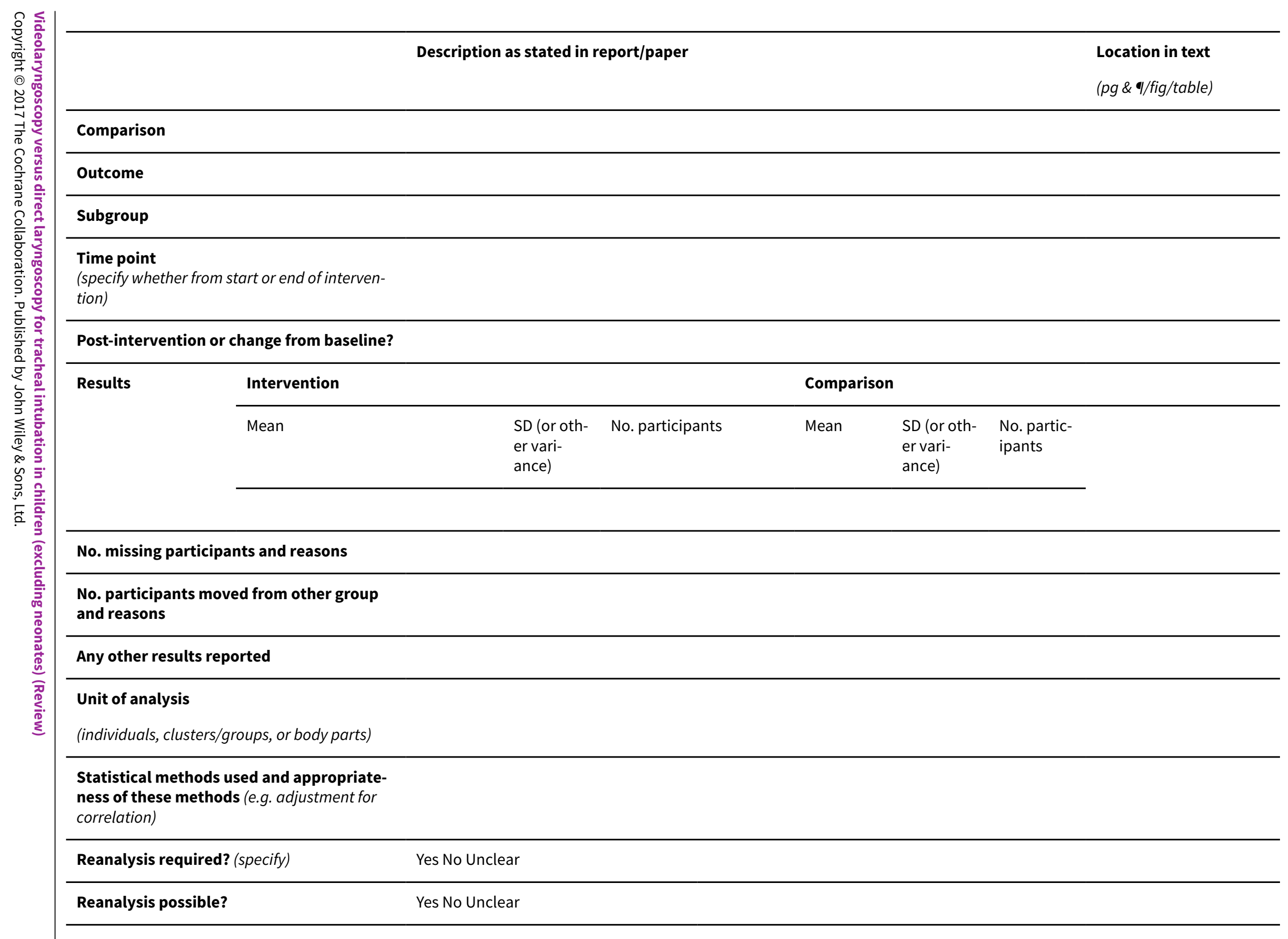




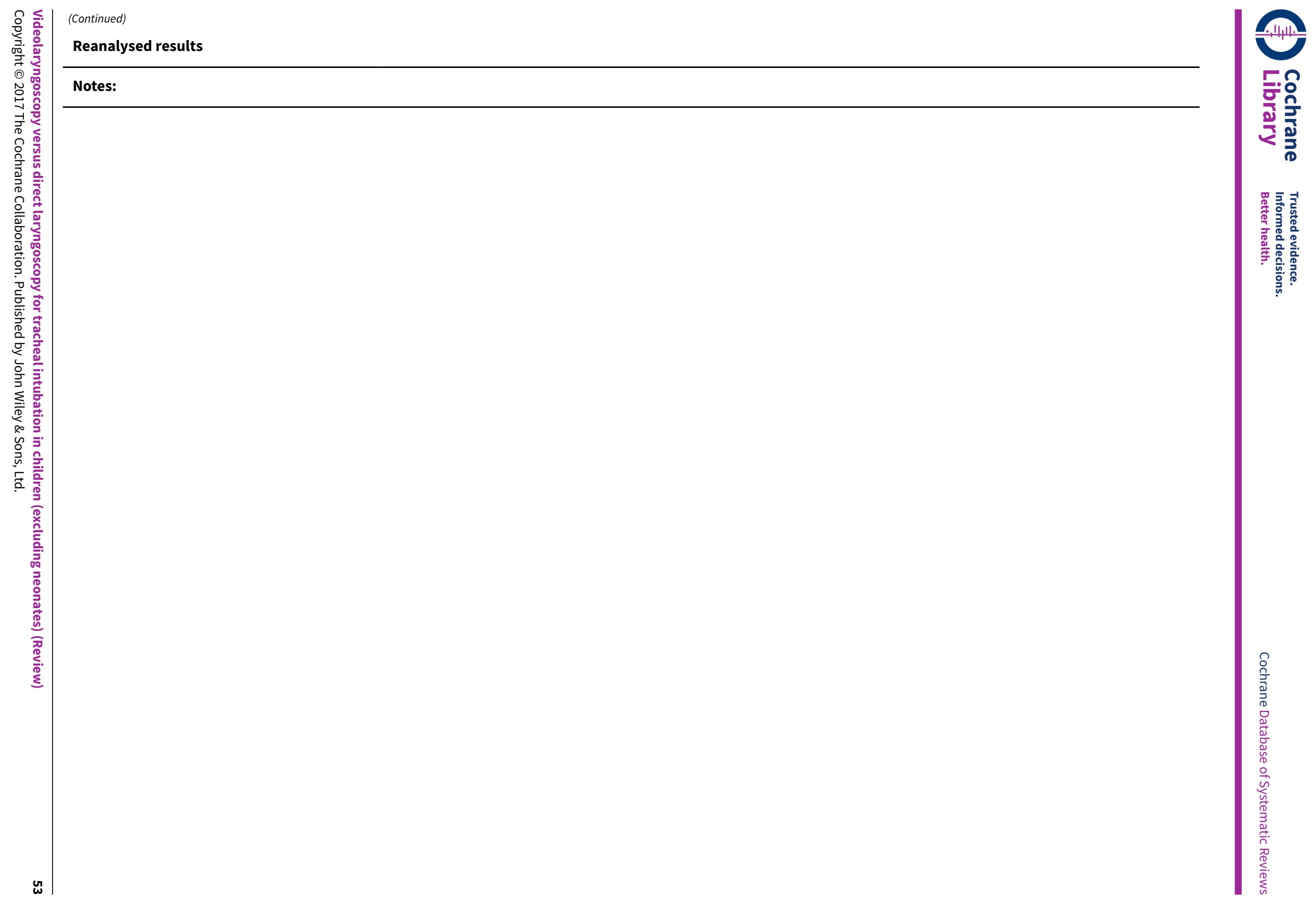




\section{Comparison}

\section{Outcome}

\section{Subgroup}

\section{Time point}

(specify whether from start or end of intervention)

\begin{tabular}{|c|c|c|c|c|}
\hline \multirow[t]{2}{*}{ Results } & $\begin{array}{l}\text { Interven- } \\
\text { tion result }\end{array}$ & SD (or other variance) & $\begin{array}{l}\text { Control re- } \\
\text { sult }\end{array}$ & $\begin{array}{l}\text { SD (or oth- } \\
\text { er variance) }\end{array}$ \\
\hline & Overall res & & \multicolumn{2}{|c|}{ SE (or other variance) } \\
\hline
\end{tabular}

No. participants

\section{No. missing participants and reasons}

\section{No. participants moved from other} group and reasons

\section{Any other results reported}

Unit of analysis (by individuals, clusters/groups, or body parts)

\section{Statistical methods used and appropri-} ateness of these methods

\begin{tabular}{ll}
\hline Reanalysis required? (specify) & Yes No Unclear \\
\hline Reanalysis possible? & Yes No Unclear
\end{tabular}

\section{Reanalysed results}

\section{Notes:}

\section{Applicability}


Have important populations been excluded from the study? (consider dis- Yes No Unclear

advantaged populations and possible differences in the intervention effect)

\section{Is the intervention likely to be aimed at disadvantaged groups? (e.g. lower Yes No Unclear}

socioeconomic groups)

\section{Does the study directly address the review question?}

(any issues of partial or indirect applicability)

Notes:

\section{Other information}

Description as stated Location in text

in report/paper

(pg \& $9 /$ fig/table)

\section{Key conclusions of study authors}

\section{References to other relevant studies}

\section{Correspondence required for further study information (from whom, what,} and when)

\section{Notes:}

\section{CONTRIBUTIONS OF AUTHORS}

Ibtihal S Abdelgadir (IA), Robert S Phillips (RP), Davinder Singh (DS), Michael P Moncreiff (MM), Joanne L Lumsden (JL).

Conceiving of the review: IA.

Co-ordinating the review: IA, JL.

Undertaking manual searches: IA, MM, DS.

Screening search results: IA, MM, DS.

Organizing retrieval of papers: IA.

Screening retrieved papers against inclusion criteria: IA, MM, DS.

Appraising quality of papers: IA, DS.

Abstracting data from papers: IA, DS.

Writing to authors of papers for additional information: IA.

Providing additional data about papers: IA.

Obtaining and screening data on unpublished studies: IA.

Managing data for the review: IA, DS, MM, JL, RP.

Entering data into Review Manager 5 (RevMan 5.3): IA.

Analysing RevMan statistical data: IA, MM, JL, RP.

Performing other statistical analysis not using RevMan: IA, DS, JL, RP.

Interpreting data: IA, DS, JL, RP.

Making statistical inferences: IA, DS, JL, RP.

Writing the review: IA, DS, MM, JL, RP.

Securing funding for the review: IA.

Performing previous work that was the foundation of the present review: IA.

Serving as guarantor for the review (one review author): IA.

Taking responsibility for reading and checking the review before submission: IA, DS, MM, JL, RP. 


\section{DECLARATIONS OF INTEREST}

Ibtihal S Abdelgadir has submitted this Cochrane Review as a research thesis for partial fulfilment of a master degree in child health.

Joanne L Lumsden received a fee from Leeds University for participating in the Critical Illness module of the MSc in Child Health and for marking assignments for this module. Dr Lumsden received a fee as Ibtihal Abdelgadir's supervisor for her MSc Child Health. This is a standard fee for supervision of MSc projects and does not pertain to the Cochrane Review in particular. These activities are unrelated to the Cochrane Review.

Michael P Moncreiff: none known.

Robert S Phillips: none known.

Davinder Singh: none known.

\section{SOURCES OF SUPPORT}

\section{Internal sources}

- None, Other.

\section{External sources}

- No sources of support supplied

\section{DIFFERENCES BETWEEN PROTOCOLANDREVIEW}

We made the following changes to the protocol (Abdelgadir 2014).

1. We included children up to 18 years of age, although the protocol upper age limit was 16 years. We did this to keep in line with the upper limit of children age used by studies done in children worldwide.

2. We updated the background to accommodate information retrieved from new evidence that has emerged since publication of the protocol.

3. We used the term indirect laryngoscopy, or videolaryngoscopy, instead of optical laryngoscopy, as the term 'indirect laryngoscopy' is easier to understand thus avoiding confusion.

4. We included human simulated studies as opposed to mannequin-simulated studies as referred to in the published protocol.

5. We added this clarifying sentence to the section on type of participants: These intubations were done in the operating room or in a controlled anaesthetic environment.

6. Data were insufficient for review authors to conduct a subgroup analysis according to age groups.

7. We used an updated search strategy to cover updated search results for the period 2014-2017. We did this to gather more sensitive results, as advised by the Cochrane Information Specialist.

\section{INDEX TERMS}

\section{Medical Subject Headings (MeSH)}

Heart Rate; Intubation, Intratracheal [adverse effects] [ ${ }^{\star}$ methods] [statistics \& numerical data]; Laryngoscopy [adverse effects] [*methods] [statistics \& numerical data]; Oxygen [blood]; Randomized Controlled Trials as Topic; Time Factors; Vocal Cords [diagnostic imaging]

\section{MeSH check words}

Adolescent; Child; Child, Preschool; Humans; Infant 